$\frac{2 \pi}{3-24+82}+3=533$

\title{
Some Fundamental Aspects of Fault-Tree and Digraph-Matrix Relationships for a Systems- Interaction Evaluation Procedure
}

\author{
H. P. Alesso \\ Lawrence Livermore National Laboratory \\ Livermore, CA 94550
}

February 28, 1982

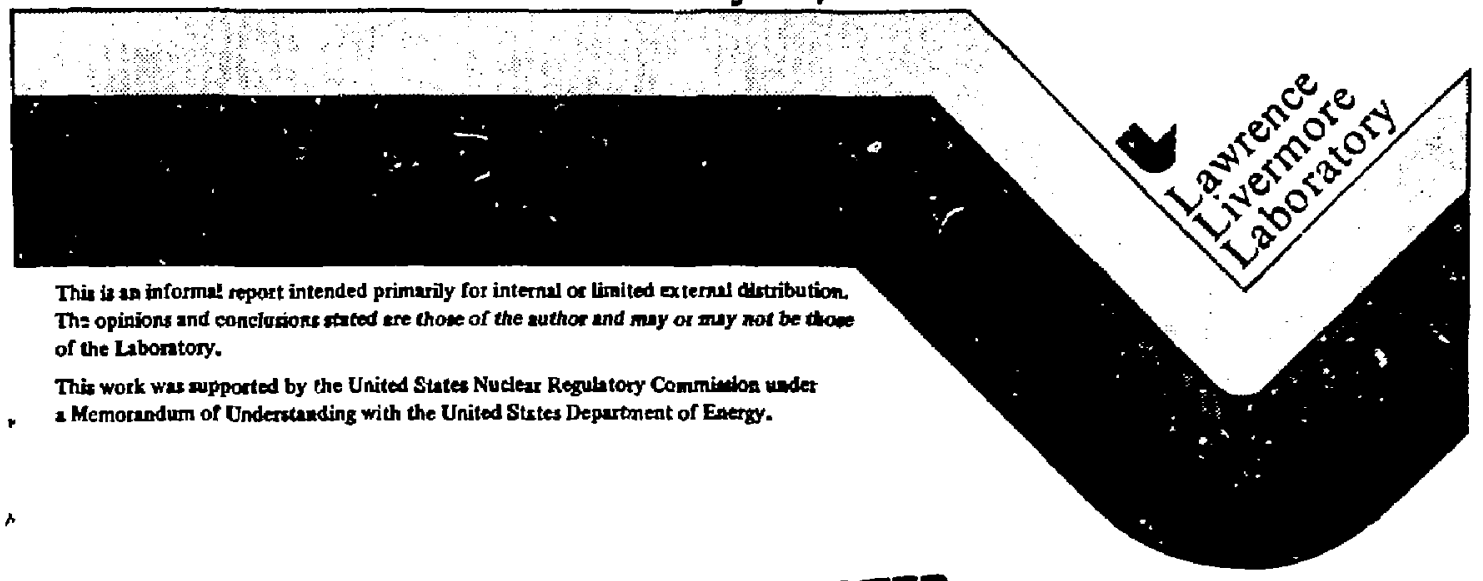

\section{MASTER}

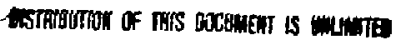




\begin{abstract}
Recent events, such as Three Mile lsland-2, Brown's Ferry-3, and Crystal Riverr-3, have demonstrated that complex accidents can occur as a result of dependent (commoncause/mode) failures. These events are now being called Systems Interactions. A procedure for the identification and . valuation of Systems Interactions is being developed by the NRC. Several national laboratories and utilities have contributed preliminary procedures. As a result, there are several important views of the Systems Interaction problem.

One vir.' is is that an enhanced Probabilistic Risk Assessment (PRA) with expanded boundary conditions and more emphasis on dependency analysis can solve the Systems Interaction problem. Alternative approaches include generic analysis, minimum-cut-set. common-cause / mode analysis, and digraph-fault tree analysis.

A second view is that techniques mathematically cquivalent to the fault-oriented risk analysis of PRA may offer more complete or more efficient analytical or computational handling of dependent failures. This view seeks to explore the utility of a digraph-matrix. success-orictrted approach.

A third point of view suggests the possibility of either heuristic or simplistic graph-based techniques. Heuristic techniques assign to a safety system a score based on some system characteristics.

This report reviews some fundamental mathematical background of both fault-oriented and success-oriented risk analyses in order to bring out the advantages and disadvantages of each. In addition, it outlines several fault-oriented/dependency analysis approaches and several success-oriented/digraph-matrix approaches. The objective is to wbtain a broad perspective of present options for solving the Systems Interaction problem.
\end{abstract}
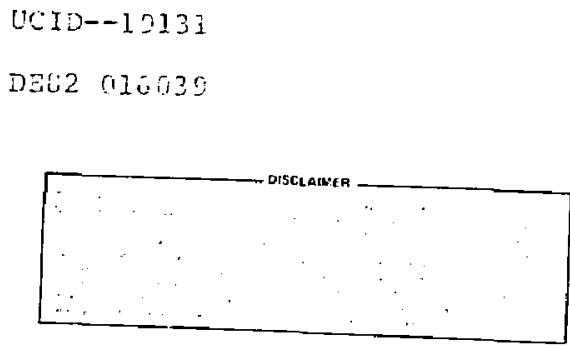


\section{Contents}

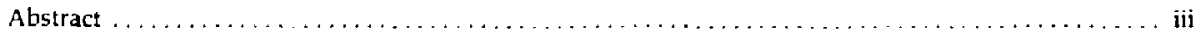

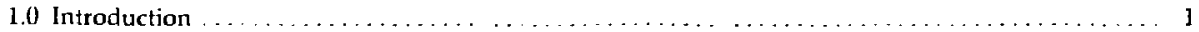

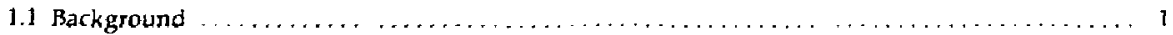

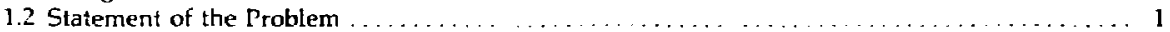

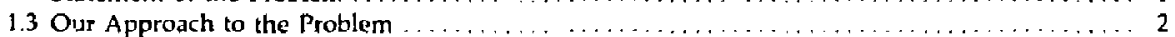

1.4 Organization of the Report . . . . . . . . . . . . . . . . . . . . . . 2

2.0 Fundamental Mathematical Background . . . . . . . . . . . . . . . . . . . . . . 3

2.1 Overview ................................ 3



2.3 Review of Sets $\ldots \ldots \ldots, \ldots \ldots \ldots \ldots \ldots \ldots \ldots \ldots \ldots \ldots \ldots \ldots$

2.4 Review of Boolean Algebra . . . . . . . . . . . . . . . . . . 5

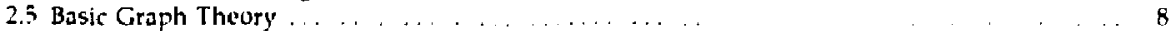

2.6 Understanding Fault Tree and Reliability Relationships $\quad$.

3.0 Outline of Systems interaction Identification Approaches . . . . . 23

3.1 Overview . . . . . . . . . . . . . . . 23

3.2 Fault Tree Approaches $\ldots \ldots \ldots \ldots \ldots \ldots \ldots \ldots \ldots \ldots \ldots \ldots \ldots$

3.3 Digraph-Matrix Approaches ........ . . . . . . . . . . . . . . 25

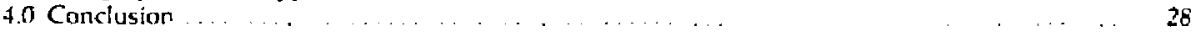

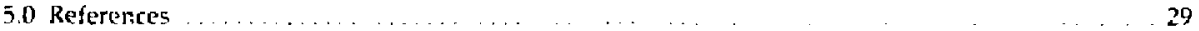




\section{List of Illustrations}

1. Structure functions for serial and parallel components $\ldots \ldots \ldots \ldots \ldots \ldots \ldots \ldots \ldots$

2. Relationships between fault trees and reliability spaces and their duals $\ldots \ldots \ldots \ldots \ldots$

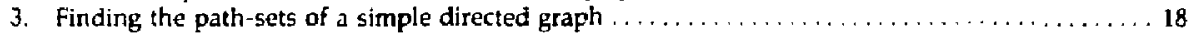



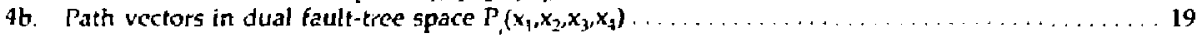




\title{
Some Fundamental Aspects of Fault-Tree and Digraph-Matrix Relationships for a Systems Interaction Evaluation Procedure
}

\author{
1.0 Intrcduction
}

\subsection{Background}

Originally, nuclear reactor design was completed without a formal risk analysis. Instead, design basis accident scenarios were poslulated. and the reactor systems were designed to safegusrd against relcase of radioartive materials under these accident conditions. Of course, scenarios could always be devised under which the reactor would release radiation. The need to balance the likelihood of a scenario with its consequences eventually led to the landmark Reactor Safety Study in 1975. "Subsequent risk analyses took on a standard format of Probabilistic Risk Assessment (PRA). Event trees were used to describe the sequence of events that led to core damage. The resulting accident sequences jdentified critical reactor systems, normally the reactor safety systems and the main feedwater system.

With this approach, fault trees are used to determine the failure probability for each system in the accident sequence. The dependence among safety systems is captured in event trees, while the dependence of two systems upon the same support system is captured in the fault trees. However, the crucial assumption in risk analysis has always been that basic events, the last events in the fault tree, are independent, i.e., $P(A \wedge B)=P(A)+P(B)$.

\subsection{Statement of the Problem}

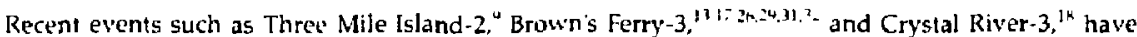
demonstrated that complex accidents can occur as a result of dependent (common-cause/mode) failures. These events are now being called Systems Interactions. These events have led us to the realization that the assumption of independence can, in some cases, be a serious error. This requires us to consider

$|P(A \wedge B)-P(A) \cdot P(B)|=c$

In other words, the difference between the actual dependency of basic events and the simple product approximation of independence leads to an error, $t$. One way to resolve $\mathrm{t}$ is to extend the fault tree analysis to a level of resolution where the new basic events are actually independent. This procedure would lead io an enhanced PRA. Alternatively, a statistical correlation analysis of the dependency, along with a sensitivity analysis, ${ }^{i}$ could be used to find out when $P(A, \quad P(B)$ is a good approximation to $\Gamma(A \wedge B)$.

In an attempt to reduce 6 , recent risk analyses, such as the Interim Reliability Evaluation Program (IREP), have included more of the instrumentation and control and support system dependence in fault trees; nevertheless, limited computational capability, lack of failure data (on support systems and human error), and limited modeling resources have necessitated assumptions that omit some dependence from each analysis. The elimination of these restrictive ass:mption is the essence of the Systems Interaction problem. 


\subsection{Our Approach to the Problem}

In this report we explore some of the fundamental mathematical aspects of fault-oriented and success-oriented risk analysis in order to find mathematically equivalent techniques. In addition, we outline several fault-oriented and digraph-matrix approaches. Our objective is to offer insight into the advantages and disadvantages of viable Systems Interaction approaches.

We present the equivalence reiationship between success-oriented (path-sets) expressions and failure-oriented (cut-set) expressions for a uniquely specified graph model. Then we explain that when a fault tree is constructed for a system with a specified top box that considers only a limited number of al! possible failure modes, that fault-1ree analysis represents a subset of a success-oriented analysis.

Furthermore, we discuss and illustrate the analytic difficulties of minimizing a Boolean expression. where such difficulties arise from eri.her a fault-tree or a success-oriented analysis. We state that even using third-generation computers (such as CDC 7600) and Nelson's algorithm (double complementation) to find the compiete set of prime implicants, the size of expression that the computer can minimize is linited. This limitation has always been the reason for preferring fault-orianted analysis for systems witich are large and complex. Indeed, it was this limitation which caused the restriction of PRA to the sifety-system level, to the exclusion of support systems, shated environmental conditions, and dynamic human error.

Unfortunately, recent reactor accidents have demonstrated that this level of modeling is inadequale. In Section 3.2, we discuss risk asse'ssment alterations that expand ard enhance the PRA approach without exceeding available computer limitations.

While such approaches seem adequate to redress the Systems Interaction problem, they have been crjticized for lack of completeness. That is, the fault-tree analysis requires an analyst to flawless]y use deductive reasoning as he works down from the top box to the basic events. There is no explicit mathematical algorithm that will result in a uniquely correct fault tree. Indeed. there is often significant varia. tion betweest analysts modeling the same system. For this reason, a success-oriented method would be preferable. In Section 2.5 we explain how. once a representative digraph of the system is constructed, a urique path-set solution (and therefore unique cut-set solution) is found by using adjacency matrices, ieachability matrices, and Boolean minimization. Nevertheless, we realize that even with fourthgeneration computers, such as CRAY-1, the combinatorics of a success-oriented analysis would face severe computc: limitation in the Boolean minimization of the model.

There is, however. an alternative. If we could partition the system digraph model into independent subgraphs, then the matrix and Boolean manipulations could be solved separately: Correctly partitioning the digraph while saving computations puts a greater butden on the analyst. Subgraph independence also hecomes a problem.

\subsection{Organization of the Report}

In Section 2 we review some fundamental mathematical aspects of fault-tree and digraph-matrix methods, including the algebra of iogic, the algebra of sets, Boolean algebra, and graph theory.

In Section 2.6 we show the ir.terrelationship between fault-oriented and success-oriented (reliability) analysis in order to demonstrate the relationship of cut sets to path sets. This is an important relationship to appreciate, since it provides comparisons of the various approaches.

In Section 3 we present preliminary outlines of Systems Interaction identification procedures for both fault-tree and tigsaph-matrix approaches. Fault-oriented approaches, including PRA, generic analysis, minimum cut-set common-cause/mode analysis, and digraph fault-tree analysis, are presented in Section 3.2. Section 3.3 introduces success-oriented, digraph-matrix approaches. 


\subsection{Fundamental Mathematical Background}

\subsection{Overview}

Specified tasks are usually accomplished using several branches of mathematics. Fault-tree analysis. for example, requires the use of Boolean algebra (which is related to the algebras of logic and sets). graph theory, and computer science (for Boolean reduction and manipulation). In this section, we present some fundamental mathematical aspects of these disciplines. This background will illustrate how these disci. plines can be brought together to provide either fault-tres analysis or a mathomatically equivalent success-oriented digraph-matrix analysis. The ubjective is to delormine if analyst effort and/or computer analysis can be made more efficient in addressing the Systems Interaction problem. For readers familiar with Boolean algebra and the relationship between poth-sets and cut-sats, a summarv is given in 5 stion $^{2}$ I.t.

\subsection{Review of Logic}

There are many ways of operating on proposinions to form new propositume An operation is said to be iruth-functional if the truth value (truth of falsity) of the resulung proposition is determined by the truth values of the propositions from which it is constructed. The investigation of truth-functional operations is called the algebra of logic. although its subject matter forms only one braneh of modern mathematical lugic." Ite 32

Negation is the simplest common example of a truth-functional operation. If i is a proposition, then its denial. not $A$. is true when $A$ is faise and false when $A$ is true. He use to stund for negation.

Another truth-functional operation is conjunction. We shall use A \& B to stand for the conjunction ? and B). The truth table for $\&$ is

\begin{tabular}{ccc}
$A$ & B & A \& B \\
\hline$T$ & $T$ & $T$ \\
$F$ & $T$ & $F$ \\
$T$ & $F$ & $F$ \\
$F$ & $F$ & $F$ \\
\hline
\end{tabular}

There are four possible assignments of truth value's to A and $B$. The only row in which $A$ \& $B$ has the value $T$ is the first row: where each of $A$ and B is true. "A $\forall B^{\prime \prime}$ stands for "A or B or both . In its truth table, the only case where $A \cup B$ is false is the case where both $A$ and $B$ are false. The expression $A \cup B$ is called a disjunction (of $A$ and $B$ ).

\begin{tabular}{|c|c|c|}
\hline$A$ & B & $A \therefore B$ \\
\hline$\tau$ & $T$ & $T$ \\
\hline $\mathrm{F}$ & $\mathbf{T}$ & $T$ \\
\hline $\mathrm{T}$ & $F$ & $\mathrm{~T}$ \\
\hline 1 & F & $\mathrm{F}$ \\
\hline
\end{tabular}

For any truth-functional operation, i.e.. any trutin table, we can introduce a special symbol, called a connective, to indicate that operation. Thus the symbols $7, \&, v, \cdots, \rightarrow$ are connectives. These five connectives suffice for most practical purposes (where $\rightarrow$ - $\rightarrow$ are conditional and biconditional connectives, respectively).

By a statement form (in the connectives ${ }^{-1}, \&, v, \rightarrow, \rightarrow$ ) we mean any expression built up from the statement latters A, B, C..., A , B,$C_{1} \ldots$ by a finite number of applications of the connectivss $ᄀ, \&, V, \rightarrow$, -. 
A statement form A logically implites a statement form B if, and only if, every assignment of truth values making $A$ true also makes $B$ true. Examples:

- A logically implies A.

- A logically implies $A \vee B$. For wheneter $A$ is true, $A \vee B$ also must be true

- A \& B logically implies A.

Literals are the statement letters $A, B, C$, and the corresponding denials of statement letters $1 A, 7 B$, $\rightarrow$ IC. By a fundamental conjunction we mean either a literal or a conjunction of two or more literals no two of which involte the same statement letter. for instance, $7 B, A \& B, 7 A_{1}$, and $A \& C$ are fundamental conjunctions, while $i$ iA, A \& B \& A, B \& A \& C \& 1 B are not fundamental conjunctions.

One fundamental conjunction $A$ is said to be included in another $B$ if all the literais of $A$ are also literals of $B$. For example, $A \& B$ is included in $A \& B, B$ is included in $A \& B$, and $7 C \& A$ is included in $A$ \& $B$ \& $\quad C$. lut $B$ is not included in $A \&$ i $B$.

A statenient form $A$ is said to be in disjunctive normal form (dnf) if either $\dot{A}$ is a fundamental : onjunction or $\Lambda$ is a disjunction of $w$ or or more fundamental conjunctions, of which none is included in enother. For example, the following statement forms are in dnf.

- B

- ic $\vee C^{\circ}$

- Av( IB\&C)

- (A\& iB) $v(\sin \&$ i $B \& C)$

Every statement form which is not a contradiction is logially equivalent to a statement form in disjunctive normal form.

We can summarize the algetra of logic as a set of statements $A$ and connectives $7, \&$, $v$. as (A. ᄀ. \& v).

\subsection{Review of Sets}

A sut is any collection of objects. In most cases, sets are defined by means of a characteristic property of the object belonging to the set. "1" in " Following are some of the basic principles used.

Notation: for a given property $\Gamma(x),\{x: P(x) \mid$ denotes the set of alt otjects $x$ such that $P(x)$ is true.

The sets $A$ and $B$ are equal if, and only if, $A$ and $B$ have the same rnembers.

Whenever $\Gamma(x)$ is a property satisfied by no objects at all, then $x: \Gamma(x)$ is a set having no memhers. $A$ sit with no members is calied the null se: or empty set.

Given sets $A$ and $B$, their union $A \cup B$ consists of all etements of $A$ or $B$ or hoth. Thus $A \cup B=\{x \in$ e $A \vee x \in B\}$. Recall from Section 2.2 that $v$ stands for the inclusive "or".

If we represent the elements of $A$ and $B$ by points within two circles (a Venn diagram), then their union consicts of all points lying within either of the two circles.

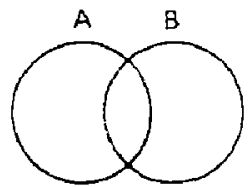

Given sete $A$ and $B$. their intersection $A \cap B$ consists of all objects which are in both $A$ and $B$. Thus,

$A-B=\{\times x A \& x \in B \mid$

Important relations between unions and intersections are given by the distributive laws ${ }^{\text {in }}$.

Firsi Distributive Law:

Second Distributive Law:

$$
\begin{aligned}
& A \cap(B \cup C)=(A \cap B) \cup(A \cap C) . \\
& A \therefore(B \cap C)=(A \cup B) \cap(A \cup C) .
\end{aligned}
$$

The complete fixed set of concern. $\lambda$, is called the universal set.

We use $\bar{A}$ to define the negation of $A$. 
The union and intersection of subsets of $X$ are again subsets of $X$. When we restrict ourselves to subsets of $X$, there is still anothes operation which can be introduced. If $A \subseteq X$, then the conlplement $\bar{A}$ of $A$ is defined to be $\bar{A}=\{x: x, x \& x<A\}$.

We can summarize the elgebra of sets as the set of sets $S$ and operators -,- as $15,-,-21$.

In general, a uniform way of determining the set-theoretrc operation sorresponding to a given logkal truth function is to express the latter in terms of $i, \&, \because$, and then replace $i, \&$, ty $\ldots$ respectively. The statement letters need not be replaced, since they can serve an sed barialen in the new expression. More explicily, an isomorphism exists between (A, T, \& , ina

\subsection{Review of Boolean Algebra}

Basics

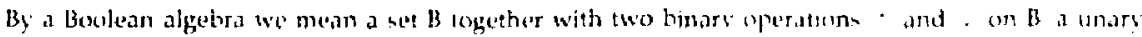
"peration on B, and two specific elements 0 and $I$ of $B$ such that the following axdom hald"

- For any and $y$ in $B, x y+y \times x+$ Communata.lam

- For any and $y$ in $B, x, y=y$.

- For ans $x, y, 1, a, x,(y: z)=(x+y)=(x+\lambda)$

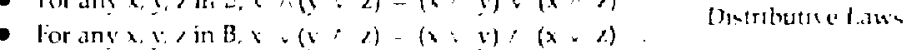

- For any $x$ in $B, x$; 3 . x

- For ani in B, $x ; 1=$ ?

- For anv $x$ in $B, x$ y $x^{\prime}=1$

- For any $x$ in $B . x \wedge x^{\prime}=0$

- $0=1$

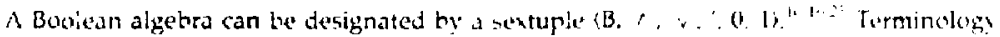

- $x \therefore y$ is called thi mert of $x$ and $y$

- $x y$ is called the join of $x$ and $x$

- $x$ is called the complement of $x$

- 0 is called the zero element.

- 1 is calles the unit element.

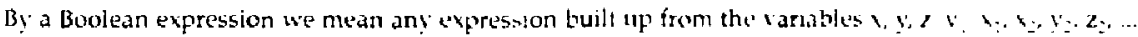
by applying the operations $A, \cdots$, a finite number of times. In other words, it al! variable's are Buolean



$A$ statement form $A$ of the algebra of logic and a Boolean expresion $;$ are said to correspond if $;$

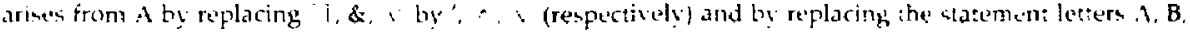
C. $A_{i}, B, C_{1}, \ldots$ by $x, y, z_{1}, x_{1}, z_{1} \ldots$ (respectively)

Civen a Boolean algeba and a Booleas mapression built up of rariables $\left(x_{i}, \ldots, x_{n}\right)$ ty applying

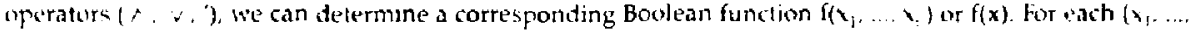
$\left.x_{1}\right)$ assigning values $\left(v_{1}, \ldots, v_{n}\right)$ respectively, and interpreting the Boolean expressim, we find fiv $\left.v_{1}, \ldots, v_{n}\right)$. If $\left(v_{1}, \ldots v_{n}\right)$ are into $(0,1)$, then $f\left(v_{1}, \ldots, v_{n}\right)$ is also into $(0,1)$

It is well known ${ }^{1}+14$ that sistem faultoriented logic diagrams such as fault trees and success" orienied reliability diagrams can be mathematically represcnted by Boolean functions $f(x)$, where $\mathbf{x}=\left(x_{1}\right.$, $\ldots, x_{n}$ ) are the binary variables representing the system's components. When $t(x)$ is an increasing function and each component is relevant, we call $f(x)$ a coherent structure function. ${ }^{+}$Once we have modeled a system and found its equivalent Boolean representation, w'e wish to eliminate irrelevant Boolean symbols thros:gh minimizing the Boolean expression.

The minimization problem consists of determining methods for finding a simplest equiv alent expressunn (see Table 1). Siace all that matters about the given expression is the truth function that it determines. the minimization solution amounts to linding one $\rightarrow$ mplest expression (or all of them) defining a given Iruth function.

To achieve this, recall that:

- li:eral $\cong$ statement letters A. B. C. ... and their denials A: B. C....

- furisinental conjunction (f.c.) $\equiv$ a literal or a conjunct (T) uf two or more literals, no two of which involve the same statement letter 
Table 1. Boolean algebra theorems.

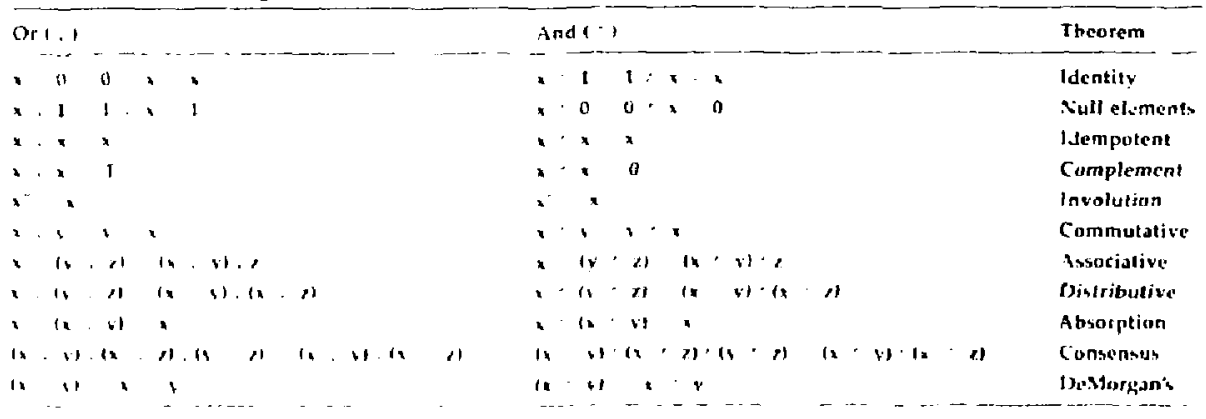

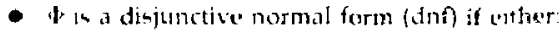

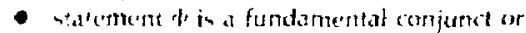

- W a disjuncion of wo ar more f.s. of which none es included in amuher.

- let J $=A B^{\prime} C$ y $A B D: A B C D^{\circ}: A B^{\circ} C^{\circ} D$

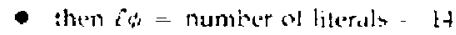
da $\cdot$ number of disiuncts $=$;

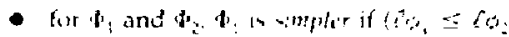

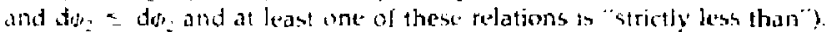

- A dnt + is minimai (matnf) for a statement form A lif $\$$ is logically equivatent to $A$ and no othar Inf is simpier than $\boldsymbol{d}$.

The reage is now set 21 minimize the Boolean expressicn. The next subiections will demonstrate how: whompliat anis.

\section{Prime Implicants}

To minmire a Buolean axpesson by finding tts prime implicanta:

- 1.él A lis a itatemeni form.

- A tondamental comiunction $\Psi$ is a premi mploant of $\mathbf{A}$ if $\Psi$ implies $A$, hut $A$ is rot Jogically impijed by any other fundamental conjunst included in $\psi$. (Note: whenever space limitations require we w replace A by juxaposition where it is nut contusing.) For example:

l. $A=A B: A B^{\prime} C: A^{\prime} B^{\prime} C$

$A B \div(A \& A) B^{\prime} C$

$=A B: B C$ lug connensu-law (sef table 1)

$A-A B \cup B C \vee A C$ Thus $A B, B C . A C$ are irme implicants Howerer at this point there is no way of knowing if these are wil the prime iopulicants.

- A modri of $A$ need not be a disjunction of all the prime implicants of $A$

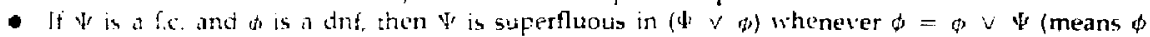
unbumes $\Psi$ ).

- A unf is irredundant if it contains no superfunus terms.

- An irredundant donf is a disjunct of prime implicants

- Anv minimal dnf must be irredundant, but an irredundant dnf need not be an mdnf.

\section{The Consensus Method lor Finding Prime implicants}

The consensus method for finding the prime implicants is:

- Ite $f_{1} f_{2}$ be $l$ wo fundamental conju actions. If there is only one letter $A$ which occurs negated in $f_{1}$ and annegated in $f_{2}$, then $f_{1} \wedge f_{2}$ is formed $y$ deleting $A$ and $A$ and omitting repetition of any other literal. This gives the consensus of $t_{1}$ and $f_{z}$. For example:

$i_{1}=A B^{\prime} C . f_{2}=A B D$.

$i_{1} \therefore f_{2}=A C D$,

then $f_{1}, f_{2} \rightarrow A B C \vee A B D \vee A C D$. 
- The consensus methed consists a film.

(1) eliminaling any disjunrt which includes zinother,

(2) adding the consensus of any wo disjuncts as a disjunct. and

(3) repeating (1) and (2) untii no longer applicable

As an example, we tan write $A D$ : $E D^{\prime}=A D$; $E D^{\prime}$. AE The tollows also illusirate the procedure:

$$
\begin{aligned}
& 4=A B C D: A B C^{\prime} D^{\prime}: A^{\prime} B C^{\prime} D+A^{\prime} B^{\prime} C^{\prime} \therefore A C^{\prime} D^{\prime}
\end{aligned}
$$

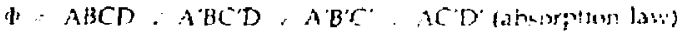

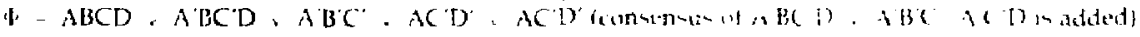

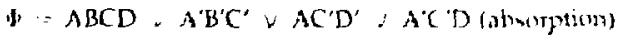

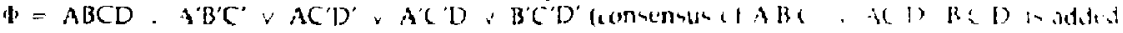

$$
\begin{aligned}
& \text { Hence, prime implicants } \left.-\left(A B C D, A^{\prime} C^{\prime} A C^{\prime} D^{\prime}, A^{\prime} C^{\prime} D, B^{\prime} C^{\prime} D\right)^{\prime}\right)
\end{aligned}
$$

\section{The Consensus Method for tinding the Minimal dnt}



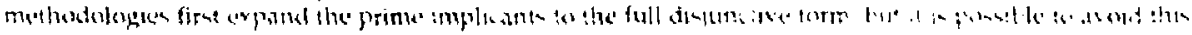

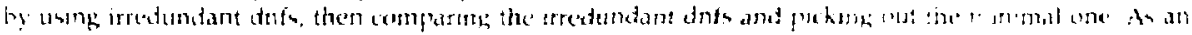
atample, se can continue the illustration a theree

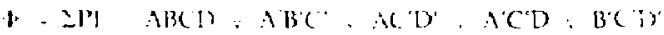

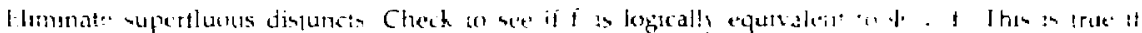

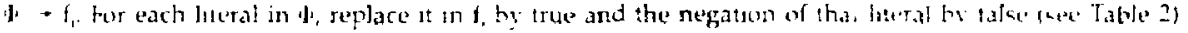

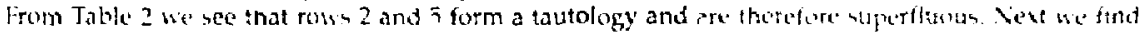
the irredundant int and select the munimum leredundant dnf equalw.

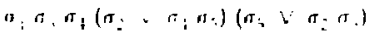

$\sigma_{1} \sigma_{2} \sigma_{1}, \sigma_{i} \sigma_{i} \forall \sigma_{1} \sigma_{2} \sigma_{1} \sigma_{i}: \sigma_{i} \sigma_{i} \sigma_{i} \sigma_{4}$

$\sigma_{1} \sigma_{;} \sigma_{i} \sigma, \forall \sigma_{1} \sigma, \sigma_{i} \sigma_{i}$ (absorpion).

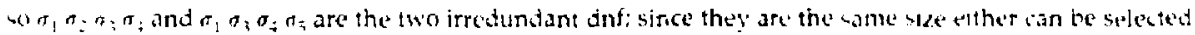
an the ind ont Chomeng the first one gives

mdirf $=A B C D \because A B C \because A C^{\prime} D: A C^{\circ} D$

Firum these last sections we realize that the analytic reduction of large Boolean equatione require the computer capabulities of complex codes such as the Set Equation Iransformation Syst'm (SETS). This is a program for mantipulating Boolean equations which is both general and flexible It can accommodate complemented events and sperial bittes. SETS can solve the Boolean equation of a fault tree for the complete uet of prime implicants.

One of the most serious limitations of fault-tree analysis, howe was is the computatior al sparo limits of present-day computers. Even the most efficient computers, such ar CRAY, are limited in the size of the Boolean equation it can efficiently reduce. For this reabin, merely drawing larger and larger fault trees to

Table 2. The replacement of literals in $\$$. Rows 2,5 form $D-D^{\prime}=1$ tautology and A. $A^{\prime}=1$ tautology.

\begin{tabular}{|c|c|c|c|c|c|c|}
\hline - & & $\begin{array}{c}a_{1} \\
A B C D\end{array}$ & $\begin{array}{c}0 \\
\mathrm{~A} \cdot \mathrm{H} C\end{array}$ & $A C D$ & $\begin{array}{c}r_{4} \\
A(t)\end{array}$ & $\begin{array}{c}o_{\hat{i}} \\
B C D\end{array}$ \\
\hline $\mathrm{l}$. & $A B C I$ & 1 & 1 & $F$ & $r$ & $r$ \\
\hline 2. & $A^{\prime} B^{\prime} C^{\circ}$ & F & 1 & $\mathbf{F}$ & D & $D^{\prime}$ \\
\hline 3. & $A C^{\circ} \mathrm{D}$ & $\mathrm{f}$ & f & 1 & s & 11 \\
\hline 4. & $A^{\prime}\left({ }^{n} D\right)$ & 1 & $\mathrm{~B}^{\prime}$ & $F$ & 1 & 1 \\
\hline & $\mathrm{HC}^{2} \mathrm{U}$ & F & $A^{\prime}$ & A & $r$ & J \\
\hline
\end{tabular}


respond to the Gistem Intera iun problem is not a completely satisfactory solution. Efficient ways of handling the defendency anat? is mus: b? found.

\subsection{Basic Graph Theory}

Graph theors is one of the simplest and most efegant suljects of modern mathematics, with a wide variefy of applications. Based an the simple idea of points connected by lines, graph theory combines thene ingrediesth into a rich andantment of forms with fexible properties, making the subject a useful tool

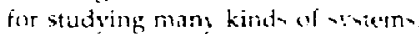

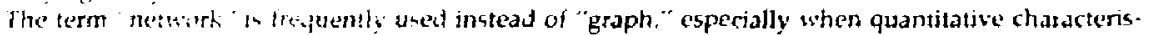
the are imparted to the poim and lines kie can speak, for example, of electrical netsorks, projer:

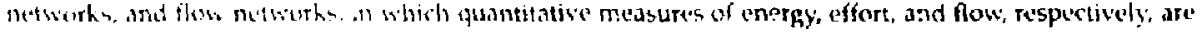
anseriated with the extgen

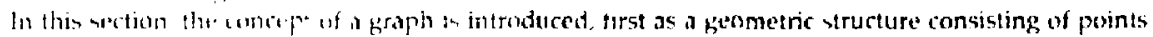

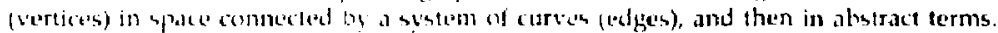

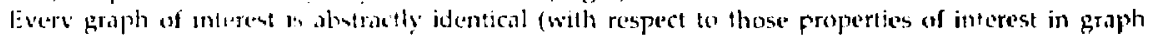
theory) with an appropriate ginstentac grapin.

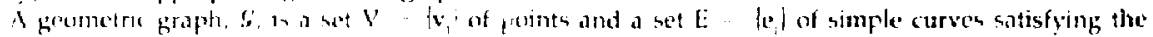
foliowing comblistrim

- Evers closed curve an : contaiis frecisedy cre point of $V$.

- Foery open carve in E contame precibely two points of $V$, and these agree with its end points.

- lhe curver in l: have nu commor puinte, except for points of $V$.

Thus graph $S^{\prime}=(\mathrm{V} \mathrm{E})^{\circ}$

A geonetric graph in simply a geometric configunation or structure consisting of a set of pointe connerted by a set of mommterenting continuous curves.

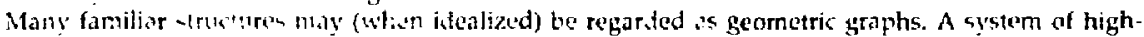

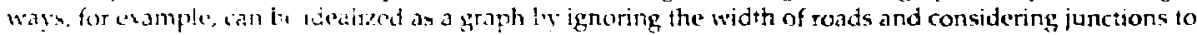
bi inints

A graph in said to be as ise if it 15 annected arid has no circuits. More generally a graph which is frees

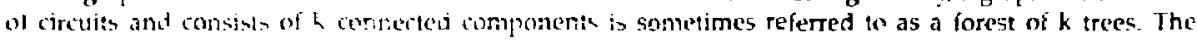
concept of a trea play a cer ra role in manv aspects of graph theory. A graph is a tree if and only if arery

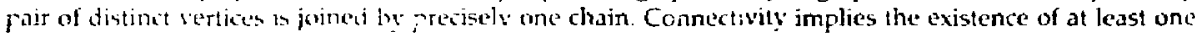
chain, while the absence of circuit-implies the existence of at most one chain

Where the emphasis in on was of enepating sets of vertices from one another, the concept uf a

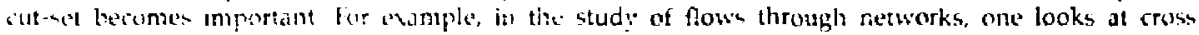


cross station which constitutes a bottleneck.

In many situatlons l: is necesat v' to assoctale an urientation or direction wi:h each edge of a graph. In

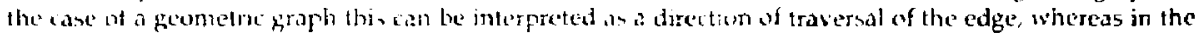

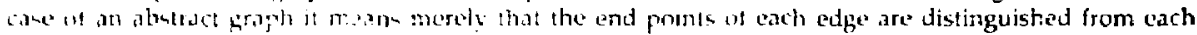

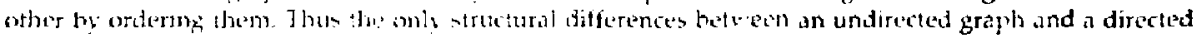


ctered pair of verticen

An are of length $n$ in a heyuence of (not nectesarily distinct) ares, $a_{1}, a_{2} \ldots, a_{n}$, ste $h$ that for an

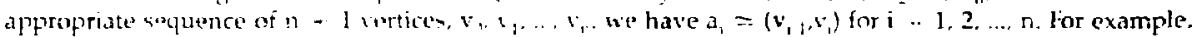
in the figure the' sequence $a_{1}, a_{1}, a_{5} a$, forms an are progression of length 4 with $v_{2}, v_{2}, v_{2}, v_{1}$, as the corresponding secquence ut verticus "

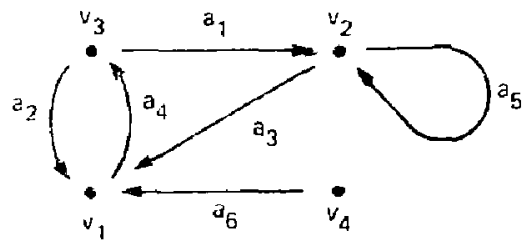


An open (closed) arc progression in a directed graph determines a comesponding open (closed) edge progression in the associated undirected graph. The converse is not generally true, however. For example, in the figure above, the sequence $a_{1}, a_{2}, a_{n}$ determines an open edge progression joining $v_{2}$ and $v_{4}$, but it fails to constitute an arc progression for lack of consistent directions.

An arc progression in which no arc is repeated is called a path progression ur cycle progression. depending on whether it is open or closed. The corresponding set of arrs, without regard to sequencing, is called a path or cycle, respectively. If the vertices $v_{0}, v_{1}, \ldots, v_{n}$ are all distinit (in which case the arcs are also distinch the , $^{\text {ath }}$ progression ar cycle progression, as well as the corresponding path or crole is said

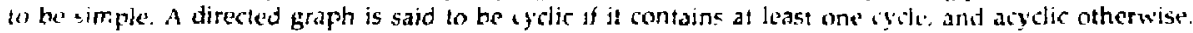
(Note that a loup is a special instance of a cycle.)

Various matrices may represent incidence relations between the terticen and adges of a graph and. more generaliy, represent incidence relations between circuits, cut-sets, chains, and the edges associated with them. These algebraic representations apply to hoth directed and undrectect graphs. Whether one manipulaten these matrices or not, they are a convenient way to record the structure of the graph. There is

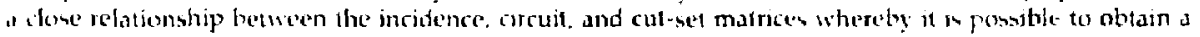

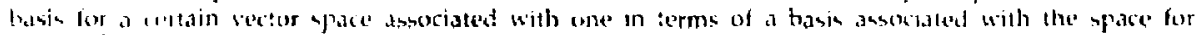
ansther. "The for evimple, factilatee the lask of determining all the wut sets of a graph ane sts circults are known loperlese of the cut-sets are closely related to the naximal fow through a network. The

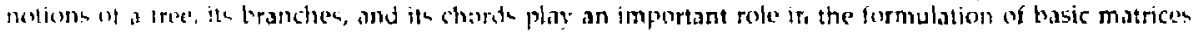
for circults and tor cat-enels.

In the ase of undirected graphs the incidence matrices have entries of 0 and 1 The addition of number in alway reduced mod 2. Thus $1+1=0$ (carry 1$) .1+0=0+1=1.0+0=0$. This chance of eniries indicate whether a property butween :wo elements holds (with entry 1 ) or dows not (with entry 0). Matrices maly be added and multiplied as usual, and then the sntries of the resulting matrix are recorded mot 2. For direcled graphs, we mav use 1. - 1. 0. since an arc, for example. may be incident with a verlex and directed away from the vertex, directed towards jt, or not incident with it at all. The mod 2 redustions are no longer adequate in this and we must consider matrices with uteper-valued entries. In fach, ihey are more cumbersome to deal with than the mod 2 matrices. However hasically the same kind of thery in olynined for the matrices of a directed graph as is obtained in the undirected case. With the idea of a malrix, we ansociate the concept of a vector space and related theory involving bases and linear combinations, of which we assume the reades has a working knowledge.

l.et $s$ be a graph having $n$ vertices and $m$ edges. The incidence matrix associated with $s$ is the $n \times m$ matrix whose raws and columns corre'spond to the vertices and edges, respertively, where each entry $a_{41}$ is I 0 b depenting on whether the jth edge is incident with the the vertex or not. For a loop, however, every roium entry is 0 . For example, the 2 -component graph shown below has the following incidence matrix:

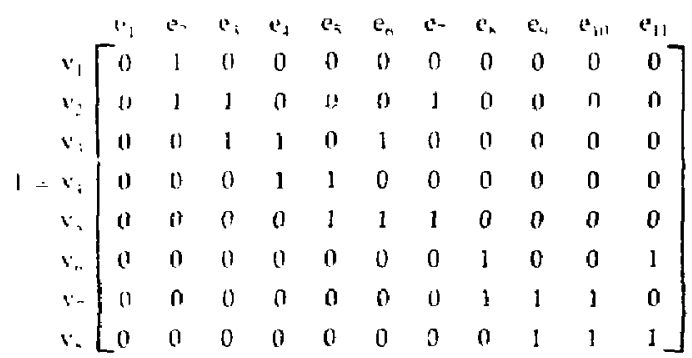
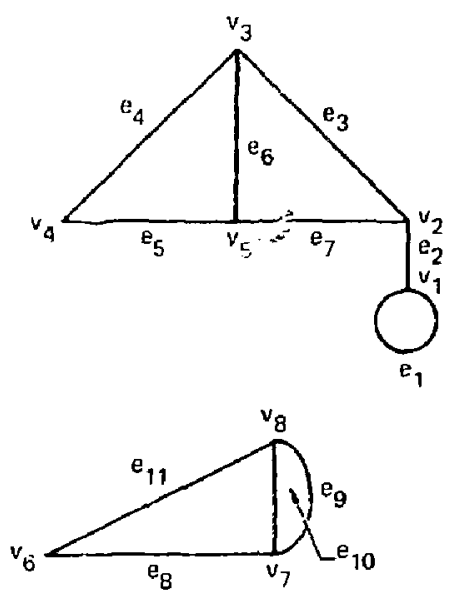
Sonte interesting properties of a graph are observed in its incidence matrix. For example, since an edge of the graph is incident with exactly two vertices, every column of its incidence matrix contains two unit entries. A loup, since it is (twice) inciónt with a single vertex, is the only exception. Hence its column $\left(e_{1}\right)$ has zero entries. Thus the incidence matrix giaes no indication of the extstence af loops, because one does not hnow whether a zero corresponds to a loop or not.

The adjacency matrix $21 \geq 2$ can be viewed as describing if there can be flow from node i to nodej. One-way flow in a network from node to node is represented by following the above definition; that is, for a pair of nodes ( $i$. j) for which flow is allowed frem $j$ to $j$ but not from $j$ to $i$ :

$\mathbf{a}_{11}=1$

$a_{1 !}=0$

A reachablay matrix" 72.27 cuntains information on all possible connections between all pairs of nodes. The determination of whether any node is reachable from any other node can be made via Boolean manipulation of the atjacency matrix. The reachability matrix can be derived from the following property: comnertion from $k$ to $n$ element * $a_{k n}$, connection from $n$ to 1 element $\because a_{n: 1}$, hence element $a_{k l}$ is

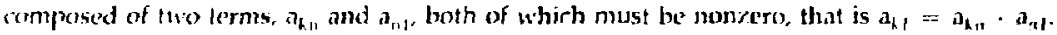

Using the Boolean product operation (Boolean AND function)

$$
\begin{array}{r}
a_{h 1}=a_{h n} \cdot a_{11} \text {, where } 1 \cdot 1=1 \\
1 \cdot 0=0 \\
0 \cdot 1=0 \\
0 \cdot 0=0
\end{array}
$$

In matrix notation, ${ }^{27}$ for a network containing n nodes

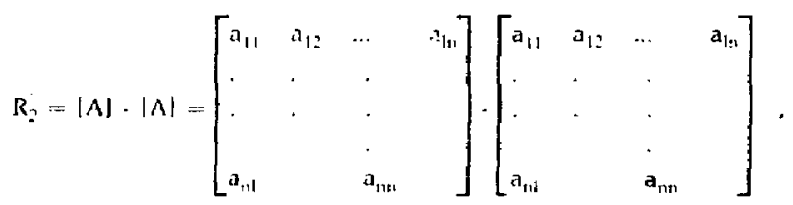

where $\mathrm{R}$ : represents the seachability matrix for all those paths which require two steps for all pairs of nodies.

For $n$ siteps the reachability matrix becomes

$K_{11}=[\Lambda]^{\prime \prime}$

lor the case of reachabiity for ald sets of path lengths ${ }^{2-}$ (n $=1$ to $\mathrm{M}$ )

$R=\sum_{a}^{\|}|A| "$, (Note: there are morte efficient algorithms for perficming thi : calculation.)

where the summation represents the Beolean sum (logical OR) operation.

$1+0=1$
$0+1=1$
$1+1=1$
$0+0=0$

and $R$ converges to a steady state vaiue. 
We now write down the proper cut-sets of the graph below, therefrom forming the cut-set matrix. each row of which characterizes one proper cut-set. The minimum cut-sets by inspection are

$\mathrm{K}_{1}=\left|\mathrm{e}_{2}\right|$

$K_{2}=\left|\mathbf{e}_{3}, \mathbf{e}_{-}\right|$

$K_{3}=\left|e_{d}, e_{i}\right|$

$K_{1}=\left|k_{1}, e_{1}, e_{t}\right|$

$K_{\bar{F}}=\left\{\mathbf{e}_{i}, \boldsymbol{e}_{-}, \mathbf{c}_{4,4}\right\}$

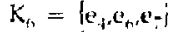

$K_{-}=\left\{e_{-1,} e_{n}, e_{-}\right\}$

and the cut-het matrix is given by

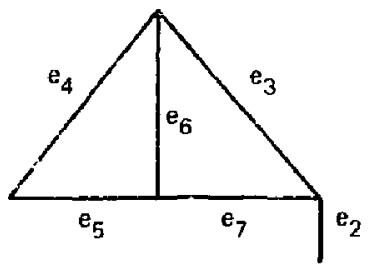

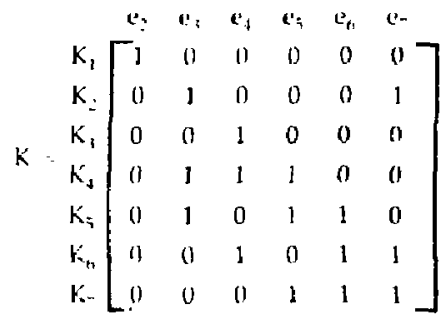

Ways of finding the cut-set matrix is an ongoing research effort in mathematics.

In a connected graph with indexed vertices, a path (properly chain) matrix, $P$, is ubtained by making its rows, $P_{1}$, the paths from the first to the last vertex, and for its columins the edges of the graph. Hence the entries of the natrix are: 1 or 0 depending on whether an edge belongs to a given path or not. For example, the graph ahove has the matrix of paths between $v$, and $v$ given by



The graphs manipulated by the reachability technique can be ejther binary ( 0 or 1 on edges) or weighted (number or symbol on edges). In the case of the weighted graph, the reachability matrix contains the identification of the path through the graph. This is show' $n^{37}$ below whese the paths from Node 1 to Node 3 are $A B+C D$.

$A=$\begin{tabular}{c|cccc} 
& $v_{1}$ & $v_{2}$ & $v_{3}$ & $v_{+}$ \\
\hline$v_{1}$ & $v_{1}$ & $A$ & 0 & $C$ \\
$v_{i}$ & 0 & 0 & $B$ & 0 \\
$v_{+}$ & 0 & 0 & 0 & 0
\end{tabular}

$R=$\begin{tabular}{c|cccc} 
& $v_{1}$ & $v_{2}$ & $v_{3}$ & $v_{4}$ \\
\hline$v_{1}$ & 0 & $A$ & $C D$ & $C$ \\
$v_{2}$ & $C$ & 0 & $B$ & 0 \\
$v_{3}$ & $G$ & 0 & 0 & 0 \\
$v_{4}$ & 0 & 0 & $D$ & 0
\end{tabular}

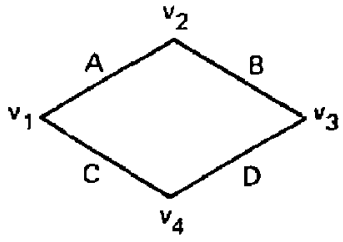


The iogical $A N D$ operation can be represerted in a relatively straightforward fashion. The figure below shows the logical AND symbol along with the Boolean equation which it represents.

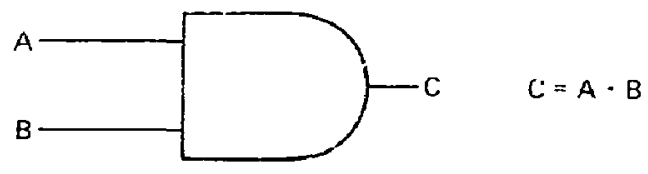

Thus an be rewitten in adjacency matrix fotmat as:

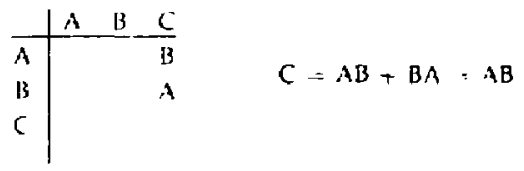

where the matrix in read in the ame from to manner as before; that ts, to get to $C$ from $A$ requires $B$.

the logical oR operation is shew' helew in adjacency matrix format as:
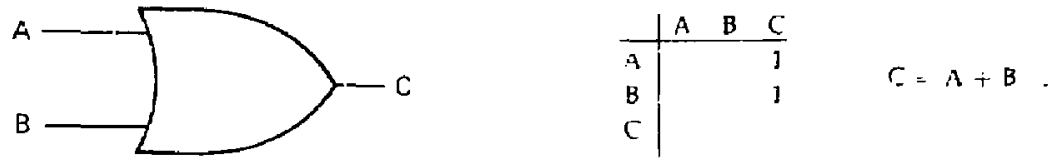

The figure bejow: is a logic network (fault-orsented digraph or fault tree) composed of Iwo AND gates and one OR gate



The individual componetıt logir adjacency matrices for this network are given below.

\begin{tabular}{l|lll} 
& A & B & E \\
\hline$A$ & & & $B$ \\
$B$ & & & $A$ \\
F & & &
\end{tabular}

\begin{tabular}{c|ccc} 
& $F$ & $G$ & $E$ \\
\hline$F$ & & & $G$ \\
$G$ & & & $F$ \\
$E$ & & &
\end{tabular}

\begin{tabular}{l|lll} 
& $C$ & $D$ & $G$ \\
\hline$C$ & & & 1 \\
$D$ & & & 1 \\
$G$ & & &
\end{tabular}


These matrices an be combined into a single adjacency matrix which represents the entire network as:

\begin{tabular}{|c|c|c|c|c|c|c|}
\hline & $\mathrm{A}$ & $\mathrm{B} C$ & $D$ & $E$ & $F$ & $G$ \\
\hline$A$ & & & & & $\vec{B}$ & \\
\hline$B$ & & & & & $A$ & \\
\hline C & & & & & & 1 \\
\hline D & & & & & & 1 \\
\hline$E$ & & & & & & \\
\hline $\mathrm{F}$ & & & & $\mathrm{G}$ & & \\
\hline$G ;$ & & & & $\xi$ & & \\
\hline
\end{tabular}

The reachability procedure can be applied to this adjacency matrex a yield the Bublean Jogic equation for the network.

Con we reach the node E from any combination of input no' 3 , alone? In answer this question, the only input nodes which will be considered are $A, 3, C$, and D, with E as the output node.

from the $A^{1}+A^{2}$ matrices ${ }^{2-}$

$E=|B G| A+\mid A C] B+\{[C] C+\{F] D$

However, the equation contains variabits other than input variables Substifution for the variables $G$ and firom the reachability matrix yielas

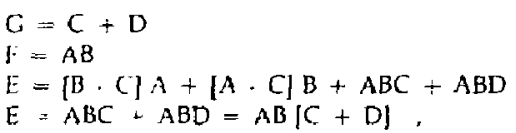

which is the logic expression for the network.

Nastice that once again we are confronted with a Boolean manipulation problem that grow's aramatically as the size of the digraph grows. While the mathematics of these teshniques has been available for many yra practical cote developmen is atill in the pesearth stage and reguires development of the state-cof-the-art algorithms.

\subsection{Understanding Fault Tree and Reliability Relationships}

\subsubsection{Overview}

Fault-tree analysis provides a quantitative and qualitative assessment of the failure characteristics of safety systems. The system is modeled as a logic diagram composed of a dirented graph with a superimposed Boolean algebra. The objective of fault-tree construction is to model system conditjons that result in an undesired top event. This restriction reduces the size of the problem.

Fault tress have notabiy been used to analyze physical systems where improved performance or indivic'ual components does not degrade the performance of the system as a whole. Such systems are called coherent structures. Non-coherence occurs whenever NOT gates are introduced into a fault-tree structure. This is most prevalent whenever human decisions play a role in instrument finctioning or, more ginerally; wheriever subsystems are found to conflict with one anothes. Fo minimize a Boolean expression of a coherent systemi only the minimal disjunctive normal form is necessary (see Section 2.4). To minimjze a Bonlean expression si a ron-coherent system one must find the complete set of prime implicants.

The objective of this section is to establish a hasis for analyzing coherent two-state systems. This will provide a perspective of the relationship between fault-oriented and success-oriented analyses. 


\subsubsection{Coherent Structure Theory}

2.6.2.] Introduction. This section examines the deterministic structural relationships between a twu state sistrm and is comporients. In particular, this saction ia consemed with syctems whose reliability performance improves when the reliahility of any component improves. Such systems are called

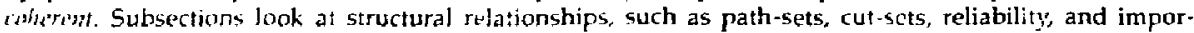
tance. in order to analyze the reliability of a system.

2.6.2.2 System Representation' $4.14,24$. A tinary variable $x$ is a variable that may assume values of zero and one only. Such a variahle is used to indicate the functioning of a system's components. The state of the ith component is given an

11 if the ith component is functioning

io otherwise

The vector $x$, demoted $x$, represents the state of $n$ components as

$x \cdots\left(x_{1}, \ldots, x_{1}, \ldots, x_{11}\right)$

The state of the syom is indicated by the binery variatele of as

$H=11$ if the rystem is functioning

in otherwise

If the componenta may he considered to determine the system, then

(i) $=\varphi(x)$.

which is called the structure function. $d$ is allowed to assume values zero or one.

In a seris's system (lig. 1a), the structure function is

$p(x)=\prod_{1}^{\prime \prime} x_{1}=\min \left(x_{1}, \ldots, x_{n}\right)$

A parallel system (Fig. lb) yialds

$w(x)=\coprod_{t}^{\prime \prime} \gamma_{1}=\max \left(x_{1}, \ldots, x_{11}\right)$.

The serites and promallel characteristics are related through

$\prod_{1}^{\prime \prime} x_{1}=1-\prod_{1}^{n}\left(1-x_{1}\right)$.

When the value of $\phi(x)$ is independent of the ith component, that component is called irrelevant. Stated mathematically, component $i$ is irrelevant if

$\phi\left(x_{1}, \ldots, 1_{1}, \ldots, x_{1}\right)=\phi\left(x_{1}, \ldots, 0_{1}, \ldots, x_{1}\right)$.

or

$\psi(1, x)=\psi(0, x)$

for all possiole $2^{n} \quad 1$ realizations of $x$. 


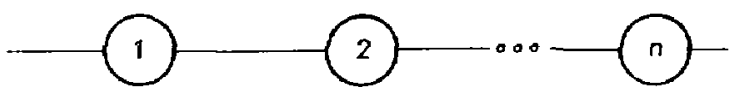

(a) $\varnothing$ series structure

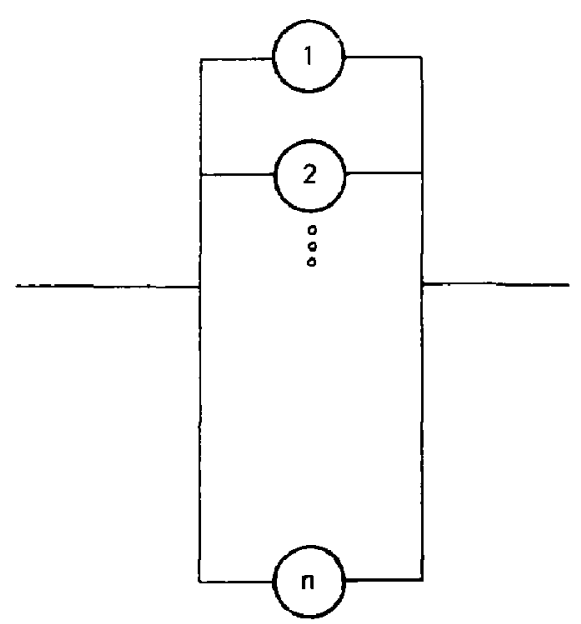

(b) \$ parallel structure

Figure 1. Strur'ure functions for serial and parallel components.

A system of components is a coherent structure if $\phi(x)$ is a nondecreasing function and each component is relevant.

Any coherent structure is bounded by

$\prod_{1}^{n} x \leq \phi(x) \leq \coprod_{1}^{n} x$

which shows that prerformance of the system is bounded below by a series system and above by a parallel sy'stem.

$A$ useful concept for analyzing systems is that of a dual space. For $\$(\mathbf{x})$, a dual structure function $\phi^{\lrcorner}(\mathbf{x})$ is defined:

$4(x)=1-\phi(1-x)$.

where $1-x=\left(1-x_{1}, \ldots, 1-x_{n}\right)$.

2.6.2.3 Path-Sets and Cut-Sets. Coherent structures may be represented in either path-set or cut-set form. A path-set is defined as a set of components whose functioning ensures the functioring of the system. Thus, a path vector $x$ yields $\phi(x)=1$. A minimum path-set is a path-set which cannot be reduced and be a patin-set; i.e. there is no subset of a minimum path-set that is a path-set. The binary funct on $p_{;}(x)$ is associated with the ith minimal path-set $P_{1}$ as

$m_{1}(x)=\prod_{1+\mathbb{E}_{1}} x_{t}$ 
This takes the salue one, if all the components in the jth minimai path-set runction; if not, the value is zero. The s:stem will function only if at least one mininal path-set is functioning

$\mu(x)=\coprod_{1}^{1} \mu(x)=\prod_{1}^{1} \prod_{1.1} x_{1}$

where $N_{1}$ - equals the number of pati-sets.

$\Lambda$ cut-set is a set of components whose fatlute results in the failure of the systern. A cut vector $x$ gives $\mu(x)=0$. The binary function $k,(x)$ is associated with the $j$ th minimal cut-sel $K_{;}$:

$k_{1}(x)=\coprod_{i, h} x_{1}$

which has the value zero if all the components of the cut-set fail, and one other vise. When at least one complete minimal cut-se: fails, $p(x)$ equals zero. This situation is represented is

$f(x)=-\prod_{1}^{t_{k}} k_{1}(x)=\prod_{1}^{b_{k}} \prod_{1, k_{1}} x_{1}$.

where $N_{B}$ equali the number of cut-sets.

\subsubsection{Fatilt Tree and Reliability Spaces and Their Duals}

While reliability analysis is concerned with tic sunctioning of the system, fault-iree analysis is con. cerned wilh system failure. Their correspondence is given by

$1 \cdots x_{1}=\begin{aligned} & 1 \text { if the ith component is functioning } \\ & 0 \text { otherwise. }\end{aligned}$

The fault tree top eqent is

$y(1-x)=1 \quad \phi(x)=\left\{\begin{array}{l}1 \text { if the system fails } \\ 0 \text { otherwise. }\end{array}\right.$

The dual relability function is

$\phi^{2}(\mathbf{x})=1-b(1-\mathbf{x})$,

the dual fault tree representation

$\Phi^{2}(1-x)=1-\Phi(1-(1-x))$

Simplified as

$\Phi(1-x)=1-\Phi(x)=1-(1-\phi(1-x))$,

then

$\phi^{3}(1-x)=1-\phi^{\Delta}(x)$.

Figure 2 demonstrates these relationships. 


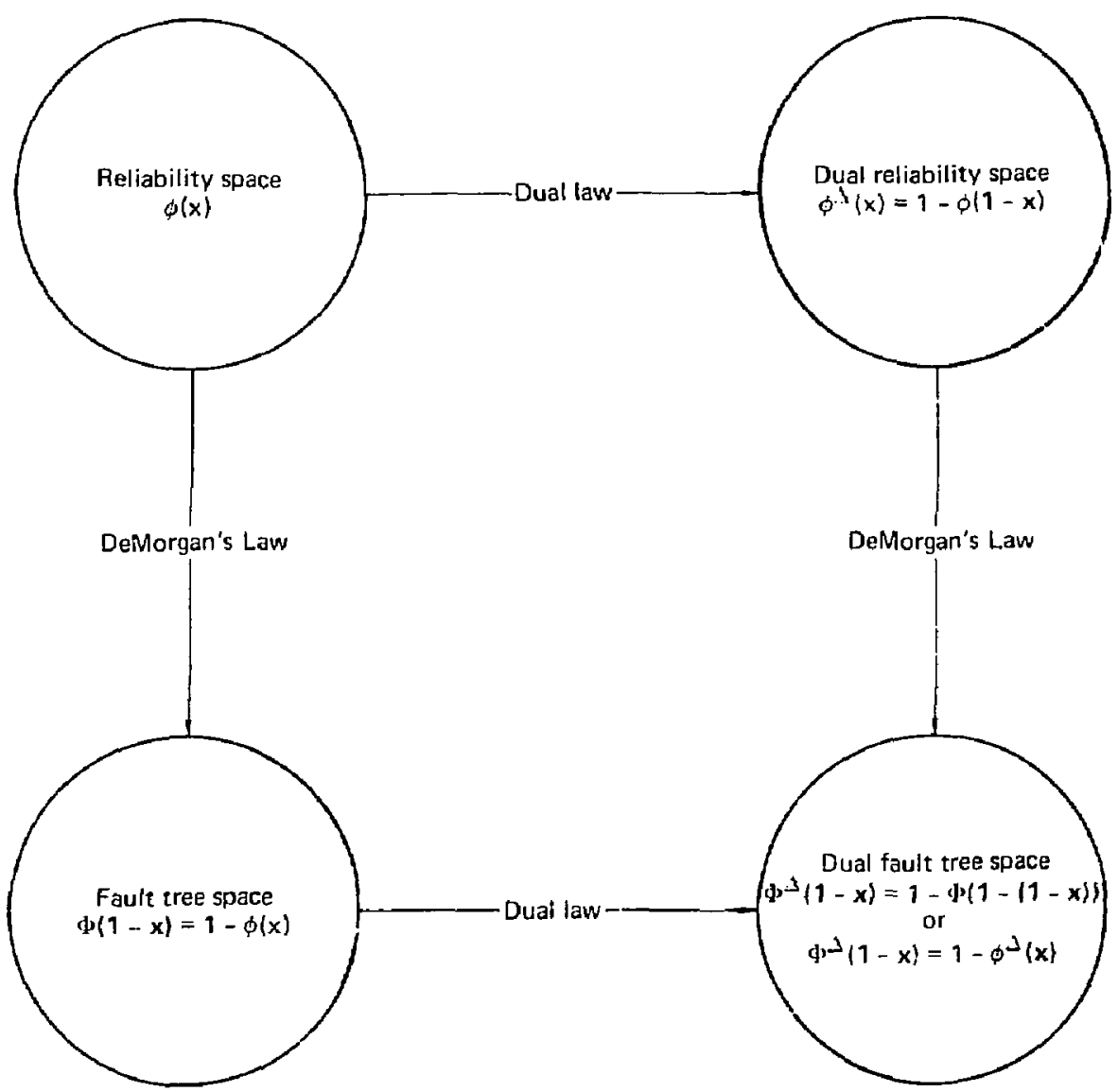

Figure 2. Relationships between fault trees and reliability spaces and their duals.

Dual space representations are often useful for mathematical manipulation. To demonstrate this relationship for fault trees, consider Fig. 3. The fault tree of this directed graph is given in Fig. 4a. Construction of the dual fault tree is accomplished by exchanging AND and OR gates to arrive at Fig. $4 \mathrm{~b}$.

Figure 2 also reveals the relationship between success-oriented reliability and fault-oriented fault tree spaces. An application of DeMorgan's law on the path-sets of reliability space yields the cut-sets of fault tree space.

To illustrate, write the sum-of-the-products (SOP) Boolean expression for the complete set of minimal path-sets of Fig. 3 ,

$\coprod_{1}^{2} P_{1}=x_{1} \cdot x_{2} \cdot \forall x_{3} \cdot x_{2}$ 


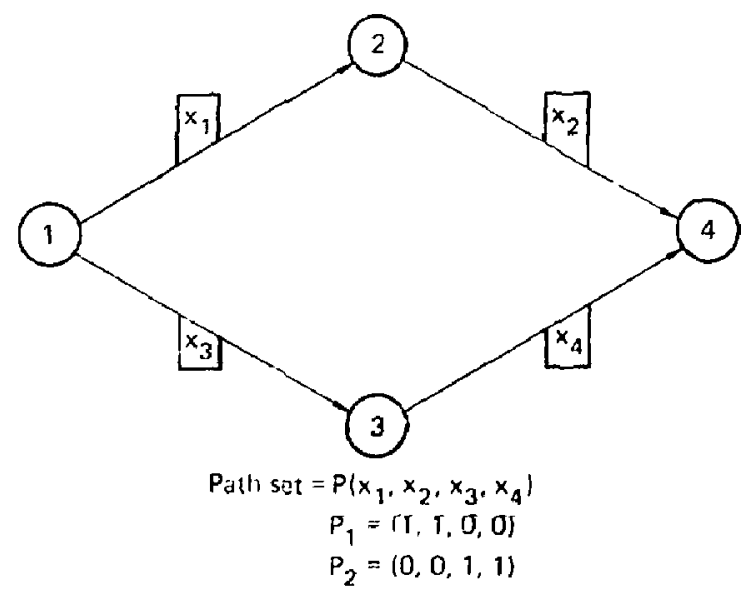

Figure 3. Finding the path-sets of a simple directed graph.

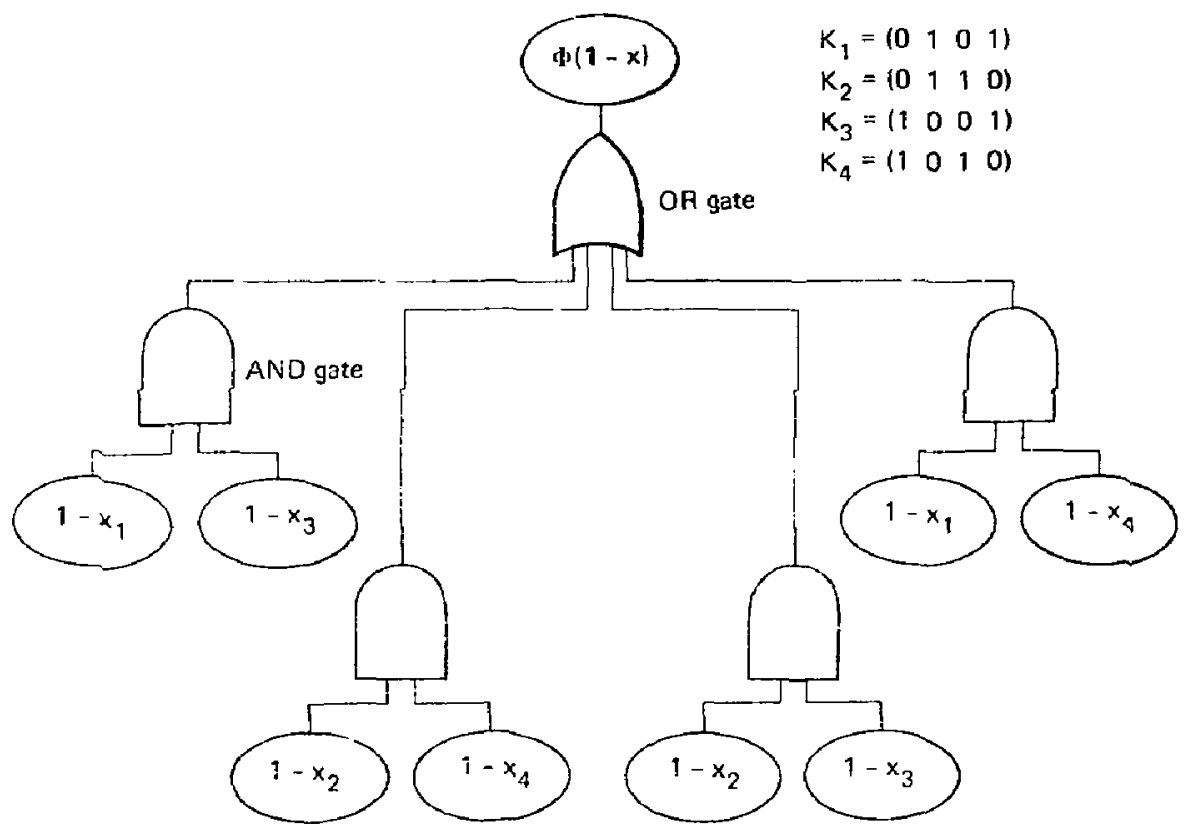

Figure 4a. Cut vectors in fault-tree space $K_{i}\left(x_{1}, x_{2}, x_{3}, x_{4}\right)$. 


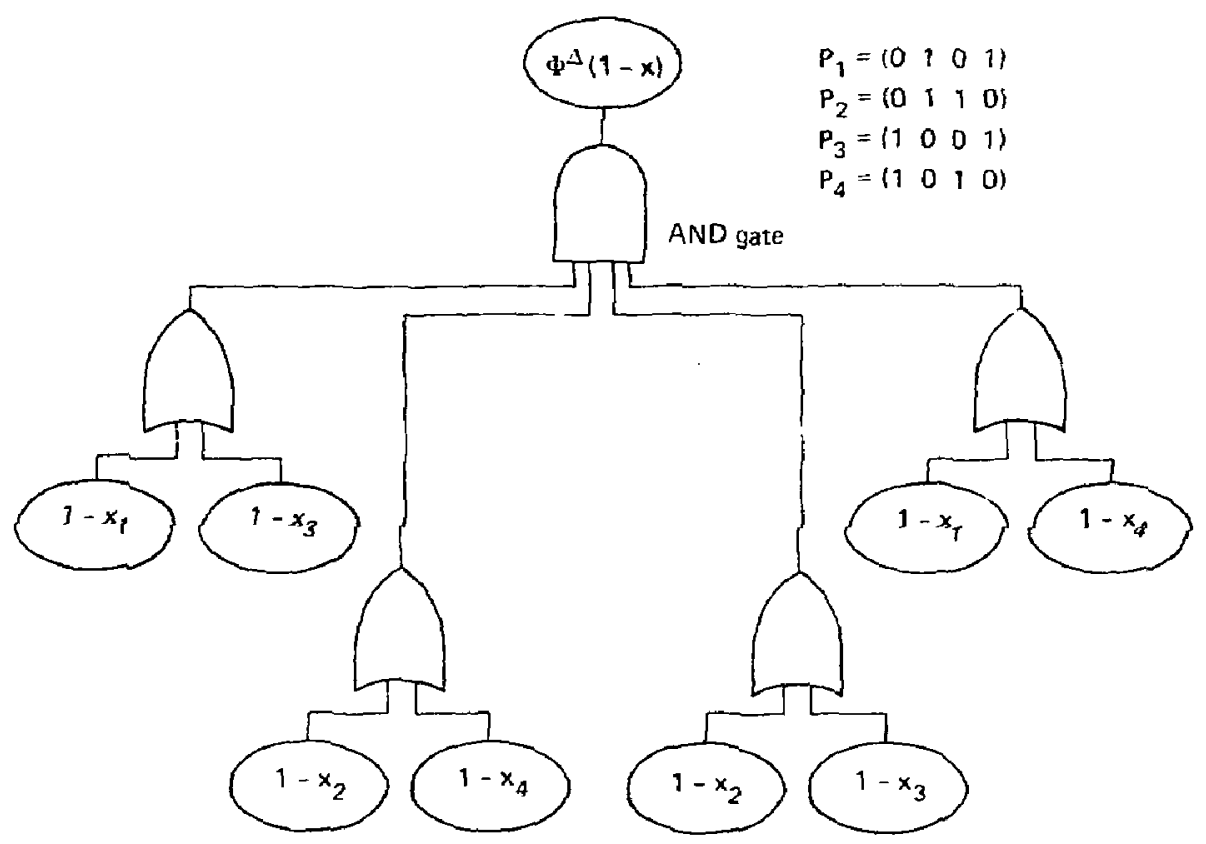

Figure tb. Path vectors in dual fault -tree space $P_{1}\left(x_{1}, x_{2}, x_{2}, x_{4}\right)$.

By application of DeMorgans Law.

DeMorgan $\left.\left\{\coprod_{i}^{2} P_{1}^{2}\right\}=1,1-x_{1}\right) \vee\left(1-x_{3} \mid \vee\left(1-x_{i} \mid\right\}_{1}^{1}\right.$.

Then

DeMorgan $\left.\coprod_{1}^{2} P_{1}=11-x_{1}\left|11-x_{4} \vee \vee 11-x_{1}\right| 1-x_{4}|\vee| 1-x_{2}\left|1-x_{3} \vee \vee 11-x_{2}\right| 1-x_{4}\right)$,

which is equal to the cut-sets of Fig. ta. Thus,

$\prod_{1} \prod_{i, k} 11-x_{1}+=$ DeMirgan $\prod_{1} \prod_{1,1} x_{1}$

19 
Thu following similarit: transform can be formed:

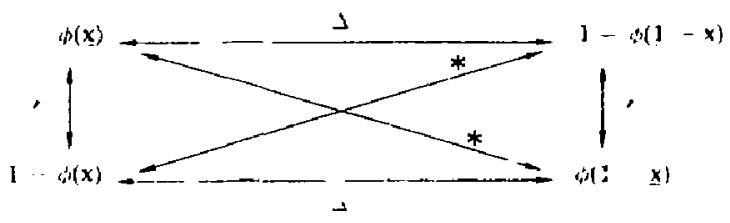

The foll noving theorem sefines a strucliare group.


structure funstion, $f(x)$.


tion bothen suctess-ariented and tate oriented analysis. It will become inymortant later in foll owing Pujpers, when relatimshiph hetween cutetets and path-sets and their duale are tused in algorithms of varione broceduren.

\subsubsection{Probability}

In entablishing a probability analysis of a coherent system, we first assunie that the compone:11s are statistically undependent. Then the probability of state $x_{1}$ of the ith component is

$P(X=1):=F X=p$ for $1-1, \ldots, n$,

where $E_{X}$ is the expected value of the random variabla $X_{1}$, and $p_{1}$ is ine retsability co the ith compnent.

The reliability uf the system is

$h=P(x(x)=1)=\operatorname{Lq}(x)$

B! assuring that the components are statistically independent, the system relability function is giv'en as a function of components' reliability:

$h-h(p)$,

where'

$\Gamma=\left(p: \ldots P_{n}\right)$.

Then

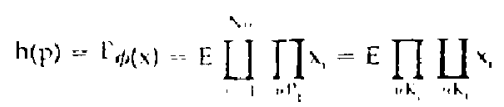

As an example, consider Fig. 3:

$h(p)=l_{1}\left[x_{1} x_{2} \vee x_{1} x_{4}\right]$

$h(p)=E X_{1} \cdot E X_{2}-E X_{1} \cdot E X_{4}-E X_{1} \cdot E X_{2} \cdot E X_{1} \cdot E X_{4} \cdot$

or

$h(p)=p_{1} \cdot p_{2} \div p_{1} \cdot p_{4}-p_{1} \cdot p_{2} \cdot p_{1} \cdot p_{1}$ 
In general, a basic event may appear in more than one minimal path-set (or cut-sei); if so, the prohability of earh path-set (cut-set) is not statistically independent. The following houndary criterica is then used:

$\prod_{1} \coprod_{i, k} p\left(x_{1}\right) \leq h(p) \leq \coprod_{1} \prod_{1, j} p\left(x_{1}\right)$

The right-hand wide of the above equation may the further simplified by a first order apresswan of the full expression, yielding

$h(p)=\sum_{1}^{2} \prod_{1} p\left(x_{1}\right)$

\subsubsection{Importance Analysis}

The arrangement of components within a system determines the importance ef certain compone'nts. for exampla, a comyonent in series can be expected to play a more important rolu than one placted in paraliel. When the state of the ith component determines if the system tunctions ar falls, : $:$ is called a critical compenent: dencribed by

$\phi(1, x) \cdot \phi(1, x j=1$.

Oit the other hand, when the ith component is given by

$d(1, x)=\psi(0, \ldots)$.

then it has no iffect on the system.

A critical path-set, $c_{1}\left(1_{1}, x\right)$, is designated te account for critical components. The total number of critical path-vecturs for component (i) is

$\left.N(i)=\sum_{i=1}|(|x| 1, x)-\infty| 0, x\right) \mid$

A measure for the structural inportance of the ith component is

$I(i)=\frac{1}{2^{n}}, N_{(i)}$

By finding and comparing $I_{\text {, }}$ (i) for each $i$, it is possible to develop an ordering of the importance of components.

Reliability inportance is another measure which takes into Lccount compunent reliability in addition to system structure. This inportance of a component can be measured by the rate at wich its reliability increases the reliability of the system. Then

$1_{h}(i)=\frac{\partial h(p)}{\partial p_{1}}=h(1, p)-h(0, p)$

where $I_{h}(i)$ is the reliability importance of the ith component, and

$l_{h}(i)=E[\phi(1, x)-\phi(0, x)]$ 
The re!abilit impontance cualuates the effert of an improvement in component reliability on system reliability by

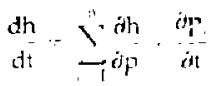

where tis time*

Similarly. "or fault trees,

$i_{1}(i)=\frac{i b}{i_{p}}$

mint

$\frac{d h}{d t}=\frac{\sum_{1}^{n}}{d p} d p$

hoshth.

\subsubsection{Summary}

The conviusion to the trawn frum lhis section is the mathematical equivalence feldtionship of fault-oriented analysis, and suceess oriented analysis when both are carried out on the seme graph for system moviel). However, "success" tends to bo associated with the efficiency of a system, the amnunt of output, the degrex of usefulness, and production and marketing features. These characterictics are describable by continuous variables which are not easily modeled in terms of simple discrete events, such as "valve dos not open," which charasterizes the failure space. (Partial failures, eg. a valve opens partially. are alno difficult e's'nts to model because o! their continuous possibilities.) Thus, the event "failure" is generally easy to define. wherr.zs the even: "stecess" may be much more difficult to tie down. Therefore, the use of failure space in analysis is much more valuable than the use of success space.

'Thas, purely from a practical point of view, the size of the population in failure space is less than the size of the population in success space. In andysis, thercfort, it is gericrally more efficient to make alculations on the basis of faitare space. Actually, all that is necessary is to shom that the analyst who considers failure space can gete his job done. Jhis has, indeed, been shown m.any times in the past. The Arawing of tree disgrams for a complex system is an expensive and time-consuming operation. When failures are considered, it may he necessary to construct only one or two ststem models, such as fault treen which cover all the agnificant tailure nodes. When succeses are considered, it may become neces-

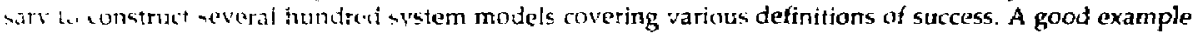

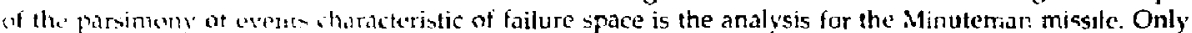
these falt treen were dyann, corresponding to the thiee undesired events-inadvertent programmed lamith, accitental motor ignition. and faut launch. It was found that careful analysis of just these three "wints involved a somplete verview of the whole complex system. ${ }^{73}$

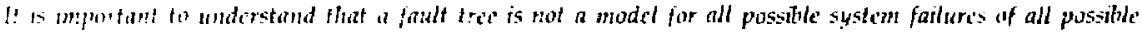

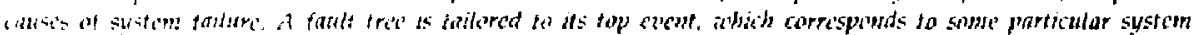
falme modi. The tault tree thus includes only those faults that contribute to this top event. Moreover, these fault are not the only pussible ones-ihey cover only the most credible faults as assessed by the aralyst. 


\subsection{Outline of Systems Interaction Identification Approaches}

\subsection{Overview}

Often several hranches of mathematics can he brought together in various ways to achieve a specified goal. The sketch of several mathematical branches prescnted in Section 2 will now be used as a background reference for several different approaches toward the ider:ification of systems interactions.

liurst, Section 3.2 presents well-established variations of event-tree fault-tree methods. Then Section 3.3 provides two preliminary outlines of viable approaches that identify systems interactions through the use of success-oriented digraph-matrix technichucs.

\subsection{Fault Tree Approaches}

\subsubsection{Reactor Safety Study Approach}

fault-tree analysis is a deductive fail tre analysis which focuses on one particular undesires event and whi h provides a method for determining causes of that event.

For a gisen accident sequence in the event tree, each system failura re quires a fault tree. Event trees id. ntify sy'st... interrelationships involsing various combinations of system sutcess and failure, control systen interrelationships, efc. The use of such event trees permits the fault trees to be constructed with freater attention to "ie applicability of the tree to its planned use and to the adequate treatment of potential common cause failures. ${ }^{2 i}$

An event tree begins with an initiating event, and as the tree is developed it defines the possithe witcomes of this event. These outcomes are determined by all the physically possible permutations encompassed by the successful operation or failure of all the applicable nuclear power plant systems that can cope with the effects of the initiating event. The event tree restricts the common-cause analysis to those combinations of subsystems pertinent to system failure.

However, an event tree containing al] mathematically pussible permutations would be far ton large to use in conducting an effeclive common-cause analysis. Therefore, the reduction of event trees is of great imprerlance 1. the handling of common-cause failures and in ensuring the ability of the methodology to logically decrease the scope of the analysis to a tractable size.

Qualitative reuuction involves the elimination of physically meaningless sequences from the mathematically complete trees. For exatnple, in those sequences involving core melt, choices conceming the sucess or failure of the reastor vessel are logically eliminated. since it 15 assumed that the vessel will surely fail.

Because each initiating event produces an event tree with many accident seyuences, a large number of sequences survives the returtion process. These sequences can be growpid with each sequence in a group receiving identical common-cause analysis treatment.

In the Reactor Safety Study (RSS), it common-cause failures were incorpurated into th: fault-tree construction in five wavs:

(1) The fault trees were constructed to meet the criteria of the systems in the event trees; the fault trees were therefore conditional. For example, if an accident sequence indicateci a severe environment, the sustem fault tree included the results presented by that environmen:.

(2) The fault trees identified components that were common to nultuple systems figiring in an accident sequence. The detection of commonality was possible because the consistent "component type" and "component identifier" make-up a unique code for each component.

(3) Each fauit tree was developed to an extremely detailed component level in order to locate single component failures and potential common-cause failures deep witinit the system.

(4) Certain: inuman failures were explicitly included in the fault trees.

(5) Test and maintenance considerations were included in the fault tree.

The study resulted in the following observations:

(1) The analyses should be developed to a level of resolution of components where failure data are generally' available. In some cases, deeper analysis was required solely 10 determine the logical relationship or to ensure independence between various inputs to a component. 
(2) When a subtree was found to be independent of other parts of the overall fault tree it was treated as a type of component.

To analyze sequences, the fault trees of all the system ialures in the sequence were combined ("ANDed" together). The Boolean analy'sis of the combined fault trees then extracted the common components and common events. This process ibentified single failures that could cause failure of multiple systems.

The ground work for this step was laid earlier in the construction of the fault trees. When an event recurred, it was given the sarne code name (eight-character event identification) so that commonalities would be obvious. When he was in doubt about the independence of given events, or about whether the events were jdentical, the analyst coded the events identically. If later Boolean amalysis indicated that these events were significant. further investigation was conducted.

To summarize, systems interaction analysis could be an expansion of probabilistic risk assessment analyis, using the same tools but with more cmphasis on dependent failures, including more support sylem analysis, shared environmental conditions, and dynamic human eroor.

\subsubsection{Generic-cause Approach}

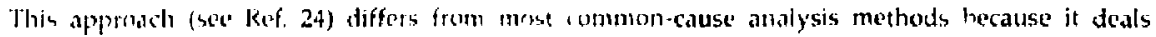
directly with minimal cut sets instead of atding secondary failures to the logic model. Thus, only component failurew which result in system failure arc considered. Partial system degradation is excluded from the analysis. This exclusion significantly redures the complexity of the analysis. Tivo additional important aspects of the techniyte are the use of generic cause's, and the nandling of component location and barrier information.

Integral parts of the method are the talles of generic causes. An txample of a generic causc is "impact". Orgnnization of these generic causes into general categories also increases the efficiency of the analyst and use of the computer.

Each hasic event is analyzed for susceptibility to generic causes resulting from environment, manufacturer, installation, etc. When a susceptibility to a given generic cause is common to all minimal cut-set members, and the location of the minimal cut-set components offers no prutection from the common causc noted, the minimal cut-sat is called a Common Cause Candidate (CCC). If the cut sat fulfills the common cause and location criteria, it "shares a common location."

\subsubsection{Minimum Cut-set Approach}

Very often, common-cause iailure analysis is implemented by adding secondary failures to the logic model. Thus complex logic models, which are already taxing the capacity of present fault-tree computer progranis, hecome more complex. To avoid this complexity, only the fault-tree minimal cut-sets are examined in this approach; secondary cients are not added to the fault tree. It is, after all, the occurrence of the events in a minimai cut-set that causes the TOP event to occur.

By limitimy the study to the fault-tree minimal cut-sets, the analysis for common causes becomes Iractable because: no additional hasic events need to be added to the logic model, no additional minimal cut-sets resuit, analwsis for commain cinses becomes ar option that can be exercised, without preplanning,

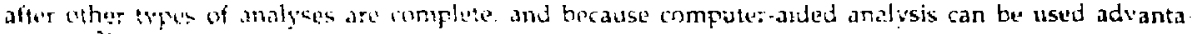
grinusly: ${ }^{+4}$

The number of possible sources of secondary failure of a component is indefinite, limited only by the analyst's knowledge and ability to conceive undesirable situations.

Other more complete descriptions of various other dependency anaiyses for systems interaction identificaton and exaluation can be found in Refs. 6, 7, 14, 15, and 24.

\subsubsection{Digraph/Fault-tree Approach}

The digraph/fault-tree method is hased an a directed graph (digraph) and construction of a fault tree. This improved version of fault tree cinstruction is particularly useful for control and instrumentation systems.

The first step in the procedure is the formulation of a general schematic for system modeling. Information from piping and instrumentation diagrams, the physical plant layout, and related procedures are used 10 formulate the schematic. The general schematic delineates the unit model digraphs needed to 
model the system and the overall system interactions. The unit models include models of utilities, environmental conditions, human actions, process equipment, and procedures.

In the second step, unit model digraphs, the basic building blocks of the procedure, are generated. Digraphs are functional cause-and-effect modiels that describe the relationships among various system variables and the conditions that are necessary for these relationships to exist. In audition, digraphs can show events. such as accident initiator actions, that may nullify or change the relationships among variables. Digraphs are usuful because they are multivalued retwork models and can readily model the dynamics of the relationships among variables. The advantage of generating unit model digsaphs is that separate analyses can be performed on system components without performing an entire sy'stems analy. sis. These unit models ate analogous to minifault trees.

The third step is the generation of the system digraph. which is constructed from the unit model digraphs, for a selected top event variable. (The tof rvent is the event being modeled.) The systen digraph is cobtained by following in detail the cause-and-effect information flow outlined in the general syistem sthemalic. The syslem js modeled as a rontrol system designed to counler adverse actions. All potential ways in which the system can respond to prevent an accident initiator are modele 1 in terms of "cancellation loops" on the system digraph. These loops are similar to the negative feedbark and negative feredforward loceps designed to cancel disturtances in process variables.

In the fourth step the system lault tree is generated from the system digraph by neans of a transformation algorithı. The lop event in the fault tree corresponds to a disturbance in the tup event variable of Wha system digraph. The loy evern sariable for assessment is TOP. defined by

rop $=\begin{aligned} & \mid-1 \text { il failure of system occurs. } \\ & \text { | o otherwise: }\end{aligned}$

A /2rovalue for a variable on the sy'stem digraph corresponds to a true or trefertid value. Hence, any other value corresponds to a deviation or disturbance. The top event in the system fault tree for the assessment is TOP $=+1$. For a disturbance in the top event variable to exist (that ic, TOP $=+1$ ) all loops in the system digraph that model the corrective actions of the system must fail. Thus, in order for system failure to occur, all protective function loops must fail.

To find the combinations of cancellation loops that must fail, we generate a fault tree from the system a.graph by means of a iransformation algorithm. The algorithm creates an AND logic gate in the fault tree for each cancellation loop that can fail.

Control loops in the systen digraph are classified according to their response range and dynamics pris to application of the transfomation algorithm. The corrective actions of loops that are too weak or tno slow results in the automatic failure of these loops. The advantage of this prior loop classification is efficiency. One need not consider all the combinatoons of events listed above that can fail these lonps.

H. lambert" discusies the dextails of the digraph fault-tree and methodology.

The qualitative analysis of the fault tree provides much valuable information without using numerical tata. It inuludes performing Boolean manipulations of the basic events, generatiof the adversary event sets, structurally ranking the hasic events, determining the collusion requirements, and evaluating the effect of powery loss on the material control system.

A structural ranking of the basic events in the event sets helps to identify important basic events for further andysis. This typu of raking is a function of the number of event sete in which a basic event appears and the relative length of those event sets.

The computer codes Fault Tree Analysis Program (FTA.P) and the Set Equation Transformation System (SETS), designed to generate and handle numerous, high-order minimal cut sets, are used to perform the qualitative analysis.

\subsection{Digraph-Matrix Approaches}

\subsubsection{Path-set Approach}

While the mathematics of using path-set approaches has tecn available for many years, practical code development is still in the research stage and the following approaches require development of the slate-of-the-art algorithms. 
The first digraph-matrix approach that we present could be called the path-set approach. It is intended to represent a more mathematically complete examination of all system failures than the usual pvent-tres fault-tree methods. The compieteness relies less on the analyst and more on computational ahilities. Its very completeness, however. leads to computational limitations restricting the size of the system it can address. This makes it more useful as an NRC review tool.

Basically. this approach (see Table 3) would stant with a traditional event tree to identify accitent sequences. Then, instead of fault-tree analysis of the systems in the accident sequence, a success-oriented analysis of the accident sequence is conducted. This step can be characterized as modeling the system in a relinbility logic diagram form (sec Section 2.6) consisting of a directed graph with a superimposed Boolean logic. A special effort would be made to include necessary support syste'ms and shared environmental conditions as jart of the digraph. In addition, human actions would be incladed as nodes in the digraph. The intention is to gonerate a Boolean expression modeling the system's successful performance.

The raw data of the system infornation comes in the form of adjacency matrices (see Section 2.5) represe'ting the "hysical connectivity of the digraph (jocluding the Boolean connections). $A$ reachability code (PATH or CIANOR) then generates all paths necessary for system funtioning. Nexl, a Boolean manipulation code, whe as the fault tree code (FTAP or SETS, see Section 2.4), generates the set of minimum pat" sets (4ec Section 2.6). The minimum path-sets represent a Boolean expression in reduced "sum of produts" form. Now the complete se: of ninimum cutsels of the system can be found by application of DeMorgan's L.nu to the set of minimum path-sets. (This was demonstrated in Section 2.6.)

Next it is ne'cessiry' to discriminate between minimum rut-sets that lead to complete system failure from those that lead to partial failure. The minimun cut-sets corresponding to complete svstem failure are then usied in the usul accident seopuence evaluation methods. This evaluation would include a qualitative importance ramking, a quantitative protability evaluation, and perhaps a sensitivity analysis.

\subsubsection{Partitioned Digraph-Matrix Approach}

In Section 2.6.3. we presented the equivalence relationship botween success-oriented (path-set) expremions and failure uriented (cut-set) expressions for a uniquely specified graph which modeled a sysien (Sou Ref. I for detailed isomorphic relationships.) However, in Section 2.6.6 we explained that a fault tree construcled for a iystem with a specified top box considers only a limited number of all possible sailure modes. and that then the fault-tree analysis represents a subset of a success-oriented analysis

In Section 2.4.2, we discussed and illustrated the analytic complexities of minimizing a Bovlean expression that cind result from either a fau!! tree or a success-oriented analysin. We stated that even a third-generation compuler (such as CDC 7obo) using Ne]son's algorithm (double complementation) to find the somplets sel of prime implicants (minimum cut-sets of a non-coherent system) was limited in the sise of exprussion that it could minimize This limitation has aluays beet. the reason for preferring fulteriented analys for hirge and complexly-modeled systems. inderd, it was this bmilation which restricted PRA to construct fault trees only to the safety-grade syatem level and not to include support statenis, sibred environmental conditions, and dynamic human error.

L'nfortunite y. teitrit reactor arcidints have demonstrated that the safety grade bystem level of mod-

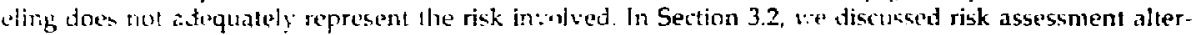
ations that expnut and enlyance the PRA approach without exceding available computer limitations.

Table 3. Overview of path-set approach.

\begin{tabular}{|c|c|}
\hline Step 1. & Traditicual ewent-trec analysis. Output: accident sequence of systems. \\
\hline Step 2. & 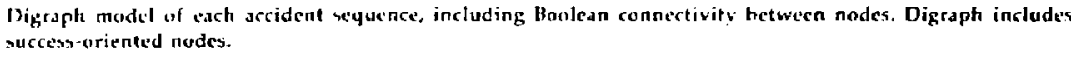 \\
\hline Step 3. & Consitı url adjucency mutrices ineluding linolean connectivity from the digraph model. \\
\hline step d. & Run reachability code (IATII or SQLEAK or CLAMORI to generate all success path-sets. \\
\hline Step 5. & Kun liooleau Imanipulation code (FTAS, SESS, SQUEAK, etc.) to find ramplete set of minimum path-scts. \\
\hline Step 6. & Apply' DeMorgan's Law to find complete set of misimum cut-sets. \\
\hline Step 7. & Evaluate which minimum cut-sels lead to complete failure of słstem as apposed to system degradation. \\
\hline tep 8. & Continue with traditional iccident sequence gvaluation methods. \\
\hline
\end{tabular}


While such approaches seem adequate to redress the systems interaction problem, they have been criticized for incompleteness. That is, the fault tree analysis requires an analyst to nawlessly use deductive reasoring as he works hackwards from the top box to the hasic events. There is not an explicit mathematical algorithm that will result in a uniquely correct fault tree. Indeed, there is often significant variation between analysts over a system. For this reason, it would be preferable to use a success-oriented method. In Section 2.5, we demonstrated how once a representative digraph of the svstem was constructed, a unigue minimum path-set solution (and therefore an unique minimum cut-set solution) is found by using atjacency matrices, reachability matrices and Boolean minimization. Nevertheless, in Section 3.3.1, when we outlined this approach, we realized that even with present day fourth-gonaration computers (such as CRAY-1) the combiratorics of a success-oriented alalysis would face severe computer limitation in the Bonlean minimizauon of the model.

There is an alternative however. If we could partition the system digraph model into separable (independent) subgraph: then the matrix and Boolean manipulations could be solved piecemeal. Cor rectly partitioning the digraph, or using unit models, while of fering computational savings. puts a greater burden on the analyst. Deciding on the independence of the subgraph also becomes an issue.

The Partitioned Digraph-Matrix Approdch slarts (see Table 4) with a traditional event tree to identify accident sequences. Then a success-oriented digraph model of the accident sequence is constructed. Special effort is to b. made to include necessary support system, environmenlal conditions, and human actions within the digraph model. Next, the digraph is partitioned into independent subgraphs ant the analyst is required to store information on the subgraphs' interconnectivity (see Sectior. 2.5). The procesdure now folluw's the path-set approach, but analyzes each subgraph rather than each digraph.

Adjacency matricts (see Section 2.5) of the subgraphs are constructed. The Bnolean relationships are incluted within the subgraph. Step 4 (see rable 4 ), then requires running a reachalility code, such as CLAMOR or PATH, to gencrate all success path-sets for each subgraph. A Boolean manipulation code. such as ITA Finally: an application of DeMtorgan's law provides the complete set of minimum cut-sets of each subgraph.

Tho burden of composing the minimum cut-sets of all subgraphs into the ninimum cut-sets of the original digraph now rests with the analyst.

The last two steps are repeats of the path-set approach which evaluate the minimum cut-sets and the accident sequences. This includes discriminating between minimum cut-sets that lead to complete and partial failure, and finally using qualitative and quantitative evaluation of the minimum cut-sets.

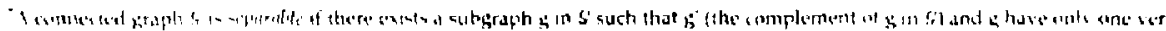

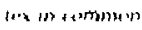

Table 4. Overview of partitioned digraph-matrix approach.

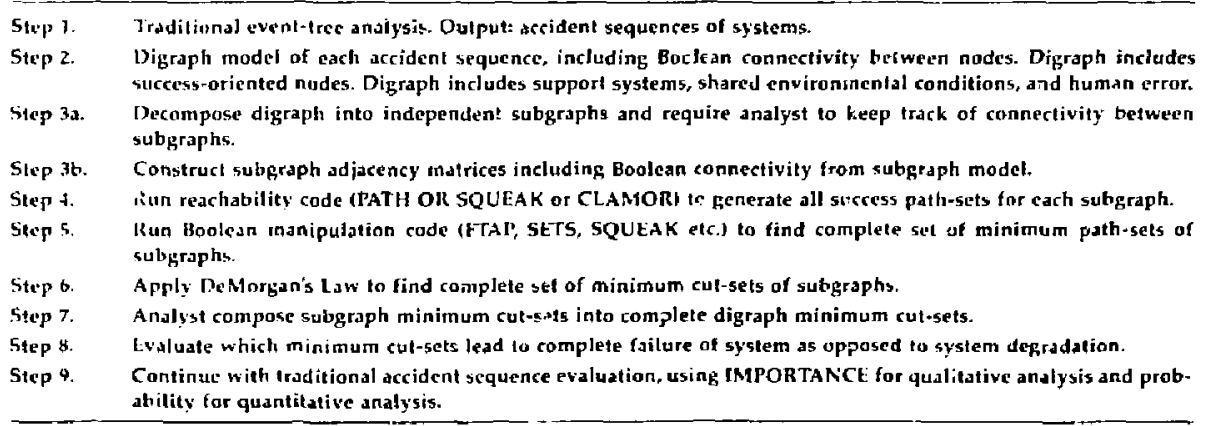




\subsection{Conclusion}

Rer'nt events such as Three Mile Island-2, Brown's Ferry-3 and Crystal River-3 have demonstrated that complex accidents can occur as a result of dependent (common-cause/mode) failures. Events of that type are now being called Systems Interactions. NRC is developing a procedure for identifying and evaluating systems interactions. Several national laboratories and utılities have contributed preliminary procedures. Several different viewpoints have emerged.

In this reporl, we have reviewed some fundamental mathematical background of both fault-oriented and success-oi iented risk analyses. This review has provided insight into some significant trade-of $f_{s}$ of each type of analysis. For example, there are computer limitations in minimizing the Boolean expression which represents the system model. Such limitation exist for both fault-oriented and success-oriented andyses. However, in the past, the success-oriented combinatorical considerations have led to more severe computer limitations, and therefore restricted it to analysis of problems smaller than those that fault-urietited analysis an deal with. Fault-oriented analysis now has a large number of trained analysts and readily available supporting comnuter codes, adding to its attractiveness

On the other hand, fault-oriented analysis requires the analyst to flawlessly use deductive reasoning as he works down from the lop event of a faule tree without an explicitly unique algorithm. The

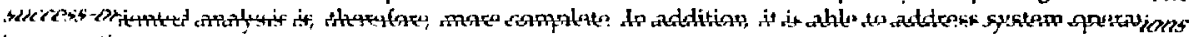
it a continuous rather than two-state fashion. which makes it particularly valuable to analyze cohtrol systems. (An exception to this is the digraph fault-tree approach discussed in Section 3.2.4.) With the availability of fourth-generation compulers (such as CRAY-1) and the possibility of partitioning digriphs into depeindent subgraphs (or unit models) the computer limitations of success-oriented approaches can become comparable to fault-oriented computer limitations. We summarize the comparison of these approaches $i_{n}$ Table 5.

Table 5. Comparison of faull-tree and digraph-matrix approaches.

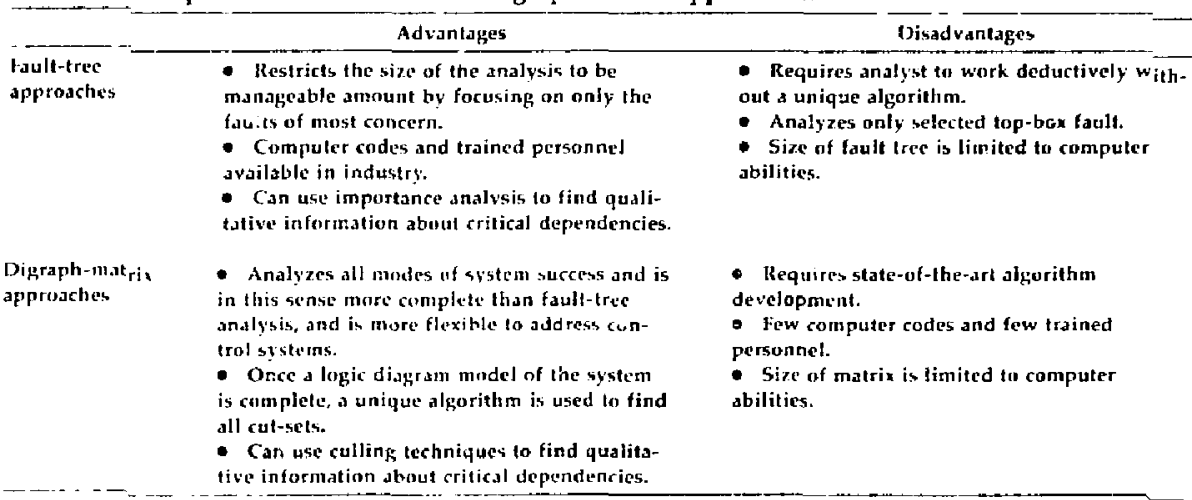




\subsection{References}

1. H.P. Alesso and H.J. Benson, "Fault Tree and Reliability Relationships For Aralyzing Noncoherent Tivo-State Systems," Nucdesr Enginzering and Design, Vol. 56, 309-320, 1980.

2. H.Г. Alesso, "Some Algebraic Aspects of Decomposed Noncoherent Structure Fin tictions," Lawrence Livermore National Laboratory, Livermore, CA, UC RL-85100, April 1979.


Winston, Inc., N.Y, 1975.

4. R.E. Barlow and H.E. Lambert, "Introduction to Fault Tree Analyis," Redisalility and Fault Trec AturtsDh, SIAM, Philadelphia, 1975 pr. 7-35.

5. R.C. Busacker and T.L. Saaty, Fumt Graphs ant Netuturks, McGraw.Hin Book Co., N.Y., 1965.

(7. A. Buslik, I. Papazoglou, and R. Bari, Brookhaven National Laboratory, "Review and Evaluation of Syctems Interartions Methods," U.S. Nuclear Regulatory Commission Report NUREG/CR 1901, January 1981 .

․ P. Gybulskis, R.S. Denning, R. Gallucci, P. Pelto, and A.M. Plummer, Battelle Memorial Institute, "Review of Systems Interaction Methudologies," U.S. Nuclear Regulatory Commission Report NUREG/CR-1896. January 1981 and Battelle Memorial Institute, Columbus, OH. Réport BM1-2073, lanuar: 1981 .

8. G.C. Corynen, Lawrence Livermore National Laboratory, "Using the Notion of

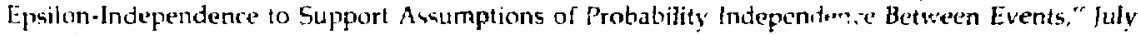
1981 (Drafi).

9. G.E Cummings, "Operator/fristrument Interactions During the Three Mile 'sland Incident," IELE

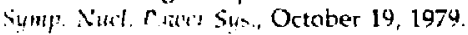

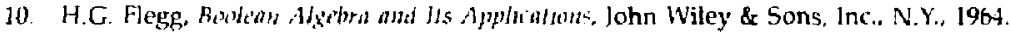

11. H.E. Lamhert, J.J. Lim, and F.M. Gilman. Lawrence l.jvermore National Laboratory. "A Digraph Fault Tree Methodology for the Assessment of Material Control Systems." U.S. Nuclear Regulatory Commissinn Report NUREG/CR-07777, May 1979, and Lawrence Livermore National Laboratory, Livermore, CA. Report UCRL.52710, May' 1979.

12. H.F. I.ambert, "Measures of Importance of Events and Cut-Sets in fault Trees," Ritradritity armd Frrodt Tre's: Amhlysis, SIAM, Philadelphia, 1975, pp. 77-100

13. G. I.anik, U.S. Nuclear Regulatory Commission, "Report on the Interim Equipment and Procedures at brown's Ferry to Detect Water in the Scram Discharge Volume," September 1980.

14. I.I. Lim, H.P. Alesso. T.R. Rice, R.K. McCord, I.E. Kelly, Laurence l.ivermore National Laboratory, "Systems Interaction Evaluation Procedure for Application to Indian Point-3," U.S. Nuclear Regulatory Commission Report NUREG/CR-2050, May 1981.

15. J.J. Lim, R.K McCord, T.R. Rice, and I.E. Kelly, Lawrence Livezono National Laboratory, "Sy'stems Interaction: State-of the-Art Review and Methods Evaluation," U.S. Nuclear Regulatory Commission Report NUREG/CR-1859, January 1981.

16. E. Mendelcon. Budinn Alythra, McGraw Hill Book Co., N.Y., 1970.

17. C. Michelson, OAEOD, memorandum to H.R. Denton, NRR, "Potential for Unacceplable Interaction Between the Control Rod Drive System and Non-essential Control Air System at the Brown's Ferry Nuclear Plant," August $18,1980$.

jo. Nuclear Safety Analysis Center and Institute of Nuclear Power Operations, "Analysis and Evaluation of Crystal River Unit 3 Incident," Joint NSAC/INPO Report NSAC-3/INPO-1, March 1980.

19. J. Olmos and L. Wolf. "A Modular Representation and Analysis of Fault Trees," Nucicar Engint'ining and Design, Vol. 48, 531-561, 1978.

20. Pacific Gas \& Electric Co.. "Description of Systems Interaction I'rogram for Seismically-Induced Events, Diablo Canyon Units 1 and 2," Revision 2, Dockets 50-275/323, July 9, 1980.

21. A.A. I'arziale and I. Sachs, "Structused Assessment Approach Version l," U.S. Nuclear Regulatory Commission Report NUREG/CR-2301, October 1979, and Lawrence Livermore National Laboratory. Livermore. CA, Report UCID-18146, October 1979.

22. A. Parziale, 1. Sachs. T. Rice, and S. Derby, "A Structural Assessment Analysis of Facility X," Vol. I, Lanrence Livermore National Laboratory. Internal Report, January 8, 1979.

23. Power Authority of the State of New York, Systems Interaction Study, December 1981, Vol. 1 and II. 
24. D.M. Rasmussen, G.R. Burdick, and J.R. Wiilson, Conmon Cause Faihure Antusıs Terhmiques: A Revisim and Comparatia' Eivaltultum, EG\&G Idaho, hac. TREE 1349, September 1979.

25. L. Rieger, Algcirac Methods of Malhe inth al Logic, Academic Press, N.Y., 1967.

26. S. Rulin and C. I.anik, U.S. Nuclear Regulatory Commission, "Report on the Brown's Ferry-3, Partial Failure to Scram Event on June 28, 1980." July 30, 1980 (with Executive Summary).

27. I. Sacks, "Techniques For The Determination of Potential Adversary Success With Tampering," Lawrence Livermore National Laboratory, Livermore, CA, Report, MC 78.978D, October 17, 1978.

28. M.I. Shooman, Prohabilistic Relinbility: Ait Enginecring Appronch, McGraw-Hill Book Co., N.Y., 1968.

29. U.S. Nuclear Regulatory Commission, "The Approach to Systems Interactions in LWRs," Reliability and Risk A ssessment Branch, June 1981 (Draft).

3). U.S. Nuclear Regulatory. Commission, "Reactor Safety Study." WASH1400 (NUREG-75/014), Octoher 1975 .

31. U.S. Nuclear Regulatory Commission, "Transient Respons" of Bahrock \& Wilcox-Designed Reactors." U.5. Nuclear Regulatory Commission Report NUREG.066?, May 1980.

32. U.S. Nuclear Regulatory Conimission. "Verbatim Transcript of Advisory Committee on Roactor Safeguard, Fluid Dynamiss Subcummittere Meeting." Tuesday. August 19. 1980, Inglewood, CA.

33. U.S. Nuclear Regulatory Commission. Frtull Trete Mandbook, NUREG.0492, January 1981. 